Sharif University of Technology
Scientia Iranica
Transactions E: Industrial Engineering
http://scientiairanica.sharif.edu
IRA I ENTIA

\title{
Economic order quantity for imperfect quality items under inspection errors, batch replacement and multiple sales of returned items
}

\author{
H. Mokhtari ${ }^{a, *}$ and J. Asadkhani ${ }^{\mathrm{b}}$ \\ a. Department of Industrial Engineering, Faculty of Engineering, University of Kashan, Kashan, P.O. Box 8731753153, Iran. \\ b. Department of Management, Faculty of Humanities, University of Kashan, Kashan, Iran.
}

Received 14 December 2018; received in revised form 25 August 2019; accepted 14 October 2019

\section{KEYWORDS}

Inventory control; Replenishment policy; Imperfect inspection process;

Batch replacement;

Type I and II errors.

\begin{abstract}
In classical inventory control problems, it is usually assumed that all of the items are of perfect quality and the inspection process works perfectly well. However, in practice, the order lots often contain imperfect items, and the inspection process is not necessarily error-free. In this article, we extended the economic order quantity model under imperfect items where the inspection process involves type-I and -II errors. The type-I error can lead to recognition of perfect items as defective, while the type-II error can result in the delivery of imperfect items to customers. In the proposed inventory problem, the customers who receive and return imperfect items wait for replacement with perfect items as a batch at the end of a special inspection process. Besides, the imperfect quality items are sold out as discounted items. Our problem considers more than one sales per cycle for returned items from market which causes a reduction in the inventory costs. We presented two cases depending on the length of the special inspection process. A numerical example was provided to compare two cases and a sensitivity analysis was discussed to assess the effect of the main parameters on the total profit.
\end{abstract}

(C) 2021 Sharif University of Technology. All rights reserved.

\section{Introduction}

Today, Supply Chain Management (SCM) has become a vital issue for companies because, through that, they can maintain their market share in complex competitive environments. The main objective of SCM is to transfer the products and services from suppliers to endpoint customers [1]. One of the efficient tools that can make more profit for supply chins is inventory management [2]. It determines when and

\footnotetext{
*. Corresponding author. Tel.: +98 3155912476 E-mail addresses: mokhtari_ie@kashanu.ac.ir (H. Mokhtari); javad.asadkhani@grad.kashanu.ac.ir (J. Asadkhani)
}

doi: $10.24200 /$ sci.2019.52075.2520 how much order placement meets customer service requirements and satisfies cost-effective production. The first classical inventory model is the Economic Order Quantity (EOQ). The EOQ determines the order lot size that holds a balance between holding costs and ordering costs in the planning horizon. EOQ's simple formulation has led to its ever-increasing application in industrial and research environments through the last century. Although EOQ is the most well-known model of inventory, some of its assumptions rarely occur in real-life situations. During the last decades, a numerous number of researches have been presented in the literature so as to improve the classical EOQ model by relaxing its basic assumptions. As mentioned above, one of these unrealistic assumptions is that all of the produced items are of perfect quality. However, in practice, defective items are received due to 
out of control production process, weak maintenance planning, failure in transportation, inadequate training of workers, insufficient work control, and weak audit process. In order to formulate the inventory policy with imperfect quality items, one of the most repeated and practical approaches is to assume that a percentage of the received or produced lots are defective. An inspection process should be instituted to recognize those items.

It is often impossible to avoid inspection errors due to human errors, on-calibrated measurement instruments, environmental factors, etc. Every inventory model under inspection errors should decide what action is needed on returning items from the market. The most common actions in literature are: (i) replacement with non-defective items and (ii) refunding with full price. In the case of replacement with a non-defective item, note that the replacement item may also be imperfect again. Delivering imperfect items to customers more than once can be detrimental to the credibility of the company and may even lead to the loss of sales. To prevent this, in this research, an inventory model with imperfect items is proposed under inspection error, which, through a complementary inspection process, ensures that the delivered items to customers who have once received imperfect items are non-defective.

The rest of this article is organized as follows. Section 2 reviews articles on classical inventory models with imperfect quality items. Section 3 provides nomenclature, assumptions, and model description and develops a mathematical model. In Section 4, a numerical example is presented to illustrate the proposed inventory model, and a sensitivity analysis is performed for the main parameters of the model. In Section 5, some of the results of the model are deduced, and possible orientations for future research are outlined.

\section{Literature review}

In recent decades, some researchers have extended the classic inventory models for imperfect items. They have used different approaches for this purpose. One of those that has recently attracted a substantial deal of attention is that the percentage of imperfect items is supposed to be a known parameter. Salameh and Jaber [3] is the first researcher that developed the classic inventory control models (EOQ/EPQ) considering this assumption. Imperfect items are recognized through a $100 \%$ inspection process and, at the end of the inspection process, are sold as a single batch at a discounted price. Hayek and Salameh [4] suggested an Economic Production Quantity (EPQ) model in which the imperfect items changed into perfect items through a rework process and backorder was allowed. Chiu et al. [5] presented an EPQ model in which the work process processed a certain percentage of imperfect items to convert them to perfect items. They also considered lower holding cost for imperfect items. Afterward, Rezaei [6] and Wee et al. [7] extended the model of Salameh and Jaber [3] with the backordering shortage allowed. Moreover, Jaber et al. [8] extended the model of Salameh and Jaber [3] considering the learning effect for imperfect items. In their research, the percentage of imperfect items follows a logistic learning curve. Rezaei and Davoodi [9] studied the supplier selection problem in a multi-item inventory model with imperfect items. They also considered a limited warehouse capacity. Chung et al. [10] proposed an EOQ where a rented warehouse could be used for holding the items. They supposed that inspection was performed simultaneously in warehouses and they investigated two cases depending on which warehouse inspection would end sooner. Chang and Ho [11] revisited the mathematical relations of Wee et al. [7] according to the renewal-reward theorem. Khan et al. [12] reviewed the extensions of this context in literature by categorizing the literature according to six specifications. Al-Salamah [13] developed an EOQ model that could not recognize imperfect items through the $100 \%$ inspection due to a destructive test in the inspection process. To do so, a single acceptance sampling plan was employed. Tsou et al. [14] considered an inventory problem with an imperfect production process where the production and rework processes were executed simultaneously. Jaber et al. [15] extended the model of Salameh and Jaber [3] for a case that replaced imperfect items with non-defective items. They provided replacement by repairing or purchasing from a local supplier. Besides, Vishkaei et al. [16] presented an inventory model that stored imperfect items after the inspection until the end of the cycle and then returned them to the supplier. Mezei and Björk [17] examined the impact of backorders on a fuzzy EPQ model. Farhangi et al. [18] developed an EOQ model with imperfect quality items where all of imperfect items were exchangeable under complete backorder. Zhou et al. [19] studied an inventory model with an imperfect production process where the manufacturer faces a one-time-only discount. In addition, Hsu and Hsu [20] suggested an EPQ model in which the shortage was completely backorderd and defective items could be sold as discounted items in three time periods: (i) immediately after inspection, (ii) at the end of the production process, and (iii) at the end of the cycle. Datta [21] established an inventory problem with an imperfect production process in which the defective rate might decrease by investing in technology, training, and so on. Likewise, the demand rate depends upon selling price and shortages are permitted. Abdel-Aleem et al. [22] determined the decision variables of an inventory-production system using a response surface methodology. They also 
assumed that there were scrap and reworkable items in the production lot. Jaggi et al. [23] considered an inventory model with imperfect quality items. It was assumed that the perfect items would deteriorate through time. Moreover, the warehouse had a limited capacity and delay in payments was permitted. Taleizadeh et al. [24] presented an EPQ model whose imperfect items become non-defective items through a rework process. They assumed that the rework process was outsourced. Mokhtari [25] considered external supplier ordering in an EPQ model for avoiding shortage in a joint production-ordering inventory problem. He determined the optimal number of subproduction cycles and EOQ simultaneously. Liao et al. [26] considered an EOQ model with imperfect items in which there were two warehouses and trade credit. They examined all possible scenarios about the duration of the inspection process and payment time. Cheng et al. [27] presented an integrated vendorbuyer inventory model with imperfect quality items. The vendor inspects own produced items and after recognition, sends out the imperfect items from the inventory system at a pre-determined cost. Mokhtari [28] discussed a manufacturing inventory model in which the order lot of raw material contained some imperfect quality (salvage) items. Besides, the production process produces some imperfect (reworkable) items. Parsaeifar et al. [2] determined the coordinated decisions on pricing, recycling, and greenness in a 3 -echelon supply chain where retailers returned the imperfect quality items to the manufacturer for recycling. Recently, Mokhtari and Asadkhani [29] studied an EPQ model with preventive maintenance in which there were two cases considered for the disposal time of imperfect quality items at the end of every production or sub-production cycle. Nobil et al. [30] proposed an inventory model with an imperfect production process involving multiple products. A fraction of products are also reworkable and scrap items.

The work presented by Yoo et al. [31] was the first research that incorporated inspection errors into inventory models under imperfect quality items. In their model, a rework process is utilized to convert: (i) the imperfect items in the inspection process and (ii) imperfect returned items into non-defective items. Afterward, Khan et al. [32] proposed an EOQ model where the inspection process was also imperfect (with possible error). Lin and Chen [33] suggested an EOQ model that in addition to the inspection errors, considered quantitative discounts and backordering shortage. Hsu [34] revisited an error in calculating the holding cost of the model of Khan et al. [32] and, then, determined the corrected optimal order lot size. Hsu and Hsu [35] presented an EPQ model with error in its inspection process. The imperfect items can be sold at a discounted price at the end of the production process or at the end of the cycle. Sharifi et al. [36] described an EOQ model in which there were inspection errors and backorder. Chang et al. [37] developed an inventory model in which items identified as defective in an erroneous inspection process as well as defective items returned by customers were sold at a discounted price. Additionally, Aggarwal and Aneja [38] proposed an inventory model where the inspection process for received batches was erroneous. They assumed that the items identified as imperfect were reworked. Jauhari et al. [39] analyzed an inventory system in a supply chain in which the manufacturer had an imperfect production process and the retailer attempted to recognize these items through an imperfect inspection process. Zhou et al. [40] suggested an EOQ model with salvage items in which the inspection process was also imperfect. Besides, they assume that backorder was allowed and delay in payment might occur. Khanna et al. [41] considered an EPQ model in which the inspection process was imperfect and the rework process was performed for return items from the market. Sofiana and Rosyidi [42] analyzed the inventory system in a two-level supply chain. The vendor produced imperfect items and also the customer had an imperfect inspection process. Khan et al. [43] introduced a vendorbuyer supply chain in which the vendor's production rate increased due to learning effect. The buyer also performed an inspection process which was error-prone. Pal and Mahapatra [44] studied an inventory system in which the production process and the inspection process were imperfect. Retailers received defective items that resulted from the manufacture[s inspection errors, and after recognizing them, there were three possible scenarios: (i) full discounting, (ii) full return to the manufacturer, and (iii) partial discounts and returns. Wangsa and Wee [45] considered a single vendor-buyer supply chain whose manufacturer had a deteriorating production process which resulted in delivering imperfect items to the buyer. The buyer also instituted an erroneous inspection process to classify and send back the defective items to the vendor.

Table 1 compares the proposed problem of this article with existing problems in the literature. As can be seen, several papers have considered inspection errors in classic inventory models with imperfect quality items. The majority of these studies replace imperfect items with the items that the inspector recognizes as perfect, while none of their models ensures delivering perfect quality items to the customers who received imperfect quality items once. Under these conditions, it is always possible that a customer will receive imperfect quality items, even more than once. Since the service level is important in real-world markets, we design a mechanism for resolving this problem in such an inventory problem. This article develops a model which replaces returned items from the market with 
Table 1. Literature review of inventory models with imperfect quality items.

\begin{tabular}{|c|c|c|c|c|c|}
\hline Paper & $\begin{array}{c}\text { EOQ/ } \\
\text { EPQ }\end{array}$ & Backorder & $\begin{array}{c}\text { Multiple sales } \\
\text { for imperfect } \\
\text { items }\end{array}$ & $\begin{array}{c}\text { Inspection } \\
\text { error }\end{array}$ & $\begin{array}{c}\text { Batch replacement } \\
\text { for returned } \\
\text { items }\end{array}$ \\
\hline Salameh and Jaber [3] & EOQ & $\times$ & $\times$ & $x$ & $\times$ \\
\hline Hayek and Salameh [4] & $\mathrm{EPQ}$ & $\sqrt{ }$ & $\times$ & $\times$ & $\times$ \\
\hline Rezaei [6] & EOQ & $\sqrt{ }$ & $\times$ & $\times$ & $\times$ \\
\hline Wee et al. [7] & EOQ & $\sqrt{ }$ & $\times$ & $\times$ & $\times$ \\
\hline Yoo et al. [31] & EPQ & $x$ & $x$ & $\sqrt{ }$ & $\times$ \\
\hline Chung et al. [10] & EOQ & $x$ & $\sqrt{ }$ & $x$ & $x$ \\
\hline Chang and Ho [11] & EOQ & $\sqrt{ }$ & $\times$ & $\times$ & $\times$ \\
\hline Lin and Chen [33] & EOQ & $\sqrt{ }$ & $\times$ & $\sqrt{ }$ & $\times$ \\
\hline Khan et al. [32] & $\mathrm{EOQ}$ & $\times$ & $\times$ & $\sqrt{ }$ & $\times$ \\
\hline Al-Salamah [13] & EOQ & $\sqrt{ }$ & $\times$ & $\sqrt{ }$ & $\times$ \\
\hline Hsu [34] & EOQ & $x$ & $x$ & $\sqrt{ }$ & $x$ \\
\hline Hsu and Hsu [35] & EPQ & $\sqrt{ }$ & $x$ & $\sqrt{ }$ & $\times$ \\
\hline Vishkaei et al. [16] & $\mathrm{EOQ}$ & $\sqrt{ }$ & $\times$ & $\times$ & $\times$ \\
\hline Sharifi et al. [36] & $\mathrm{EOQ}$ & $\sqrt{ }$ & $\times$ & $\sqrt{ }$ & $\times$ \\
\hline Mezei and Björk [17] & EPQ & $\sqrt{ }$ & $x$ & $x$ & $\times$ \\
\hline Chang et al. [37] & EOQ & $\times$ & $\times$ & $\sqrt{ }$ & $\times$ \\
\hline Aggarwal and Aneja [38] & $\mathrm{EPQ}$ & $x$ & $x$ & $\sqrt{ }$ & $x$ \\
\hline Jauhari et al. [39] & EOQ & $\times$ & $\times$ & $\sqrt{ }$ & $\times$ \\
\hline Hsu and Hsu [20] & $\mathrm{EPQ}$ & $\sqrt{ }$ & $\sqrt{ }$ & $\times$ & $\times$ \\
\hline Zhou et al. [19] & EOQ & $\sqrt{ }$ & $\times$ & $\sqrt{ }$ & $\times$ \\
\hline Taleizade et al. [24] & EPQ & $\sqrt{ }$ & $\times$ & $\times$ & $\times$ \\
\hline Khanna et al. [41] & EPQ & $x$ & $x$ & $\sqrt{ }$ & $x$ \\
\hline Khan et al. [43] & $\mathrm{SC}$ & $\times$ & $\times$ & $\sqrt{ }$ & $\times$ \\
\hline Sofiana and Rosyidi [42] & EOQ & $\times$ & $\times$ & $\sqrt{ }$ & $\times$ \\
\hline Pal and Mahapatra [44] & $\mathrm{EPQ}$ & $\times$ & $\times$ & $\sqrt{ }$ & $\times$ \\
\hline Liao et al. [26] & EOQ & $\times$ & $\sqrt{ }$ & $\times$ & $\times$ \\
\hline Parsaeifar et al. [2] & $\mathrm{SC}$ & $x$ & $x$ & $\times$ & $x$ \\
\hline Wangsa and Wee $[45]$ & EOQ & $\sqrt{ }$ & $\times$ & $\sqrt{ }$ & $\times$ \\
\hline Mokhtari and Asadkhani [29] & $\mathrm{EPQ}$ & $\times$ & $\sqrt{ }$ & $\times$ & $\times$ \\
\hline This paper & EOQ & $\times$ & $\sqrt{ }$ & $\sqrt{ }$ & $\sqrt{ }$ \\
\hline
\end{tabular}

a batch containing perfect quality items by a perfect inspection process. Moreover, due to the reduction of the holding cost, some of the literature researches assume more than one sales per cycle for imperfect quality items. Therefore, we also add such flexibility to our proposed model where holding cost is high and multiple sales of returned items can occur.

\section{Mathematical modeling}

This section describes and formulates the proposed inventory problem. For this purpose, the nomenclature used throughout this paper is given first. Then, the model assumptions are introduced and the inventory problem is then described. Finally, based on the nomenclature and assumptions, the model is formulated and the optimal order size is calculated.

\subsection{Nomenclature and assumptions}

We utilize the following nomenclature throughout this article.

\section{Parameters and variables}

y Order size (decision variable)

$D \quad$ Demand rate per unit time

$k \quad$ Ordering cost per order 
C Variable purchasing cost per unit

$h \quad$ Holding cost per unit per unit of time

$S \quad$ Selling price of a non-defective item per unit

$V \quad$ Selling price of a defective item per unit

$p \quad$ Probability that an item being defective

$\alpha$

$\beta$

$f(p) \quad$ Probability density function of $p$

$f(\alpha) \quad$ Probability density function of $\alpha$

$f(\beta) \quad$ Probability density function of $\beta$

$x \quad$ Regular inspection rate per unit time

$d \quad$ Regular inspection cost per unit

$c_{a} \quad$ Cost of accepting a defective item

$c_{r} \quad$ Cost of rejecting a non-defective item

$t_{1} \quad$ Regular inspection time per cycle

$t_{2} \quad$ Special inspection time per cycle

$u \quad$ Special inspection cost per unit

$\pi \quad$ Waiting cost per unit per unit of time

$w \quad$ Number of discounted sales of returned items per cycle

$T \quad$ Inventory cycle length

$B_{1} \quad$ Number of items that are classified as defective per cycle

$B_{2} \quad$ Number of defective items that are returned per cycle

$E[*] \quad$ Expected value

TP Total profit per cycle

TRU Total revenue per unit time

TCU Total cost per unit time

TPU Total profit per unit time

We consider the following assumptions for constructing the mathematical model:

- Inventory model contains a single stage with a single item;

- Demand rate is constant, known and continuous;

- All of the demand should be satisfied;

- Lead time is assumed to be zero;

- The replenishment is instantaneous;

- Order lot contains defective items;

- The percentage of defective items is a random variable;

- All items are inspected in a regular process;

- The regular inspection process is imperfect (with possible error).

\subsection{Description and formulation}

As mentioned before, we aim to develop an inventory control model with imperfect quality items under inspection errors, batch replacement, and multiple sales of returned items. Figure 1 illustrates the behavior of the inventory level during the inventory planning horizon. The buyer orders a lot of size $y$ from a vendor that contains a percentage of the defective items $p$. Immediately after receiving the order, the regular inspection process begins in order to identify defective items. The inspection process evaluates the quality of all received items under a $100 \%$ inspection process. During the inspection interval $t_{1}$, the inspection process operates under known screening rate $x$ and inspection cost per unit $d$. It is also assumed that the regular inspection process is imperfect. The imperfect inspection process results in two types of possible error. The type-I error occurs if inspector recognizes a non-defective item as defective one, while type-II error occurs if the inspector recognizes a defective item as a non-defective one. In addition to two types of error, there are two other possible choices by inspector which are without error: (i) When defective items are recognized as defective ones and (ii) When nondefective items are recognized as non-defective ones.

In summary, we can classify items into four possible cases after the regular inspection process. Case I indicates non-defective items which are recognized as non-defective items, Case II is related to non-defective items which are recognized as defective items (type I error), Case III contains defective items which are recognized as defective items, and Case IV includes defective items which are recognized as non-defective items (type II error). The number of items in each case can be calculated as follows:

Case I:

$$
y(1-p)(1-\alpha)
$$

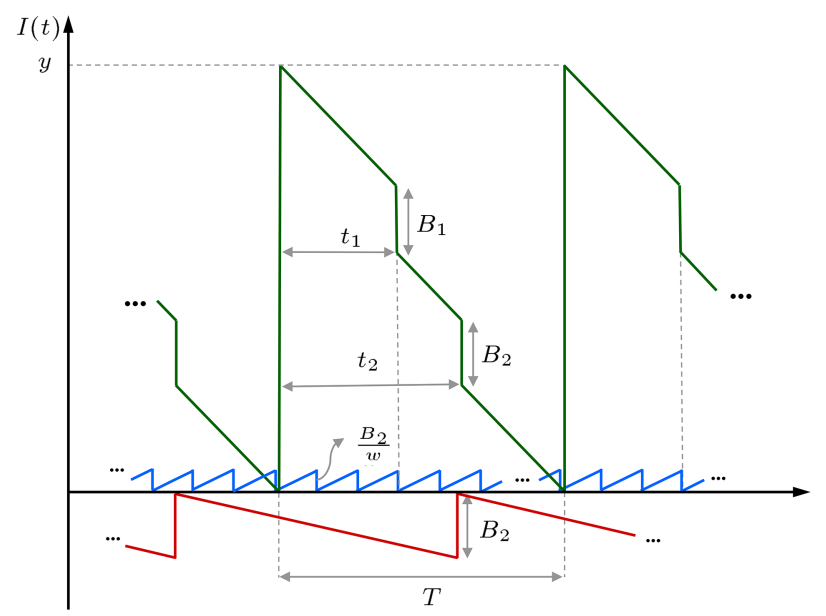

Figure 1. The inventory level over time. 
Case II:

$$
y(1-p) \alpha,
$$

Case III:

$$
\text { yp }(1-\beta),
$$

Case IV:

$$
\text { yp } \beta \text {. }
$$

A number of items that are recognized as defective (Cases II and III), denoted by $B_{1}$, are sold at the end of the regular inspection process. The inspector recognizes $B_{2}$ number of defective items as non-defective ones by mistake and delivers them to the customer. Then, the customer recognizes these items as defective and then, returns them. Therefore, these items are sold at a discounted price per unit $V$. These returned items are sold based on multiple sales through batch of size $w$. The quantity of $B_{1}$ and $B_{2}$ can be obtained as follows:

$$
\begin{aligned}
& B_{1}=y \alpha(1-p)+y p(1-\beta), \\
& B_{2}=y p \beta .
\end{aligned}
$$

If we subtract $B_{1}$ and $B_{2}$ items from the batch items, the remaining items are consumed in order to satisfy the demand. By substituting $B_{1}$ and $B_{2}$ into $T$ and simplifying the result, we have:

$$
T=\frac{y-B_{1}-B_{2}}{D}=\frac{y(1-p)(1-\alpha)}{D} .
$$

It is obvious that for avoiding the shortage, the number of items used for satisfying the demand must be at least equal to demand in cycle length. Therefore, we have:

$$
y E(1-p) E(1-\alpha) \geq D T \text {. }
$$

Also, for avoiding shortage in the regular inspection process, the regular inspection rate in every period must be large enough that can still satisfy the demand after subtracting $B_{1}$ and $B_{2}$ items. So it can be concluded that:

$$
x E(1-p) E(1-\alpha) \geq D \text {. }
$$

To ensure that customers do not receive defective items more than once in every cycle, we need a special inspection process. The customers that receive defective items as non-defective items return them. To ensure they receive non-defective items for the second time, they have to receive items through special inspection. The special inspection process starts immediately after the regular inspection process and its purpose is to separate $B_{2}$ non-defective items from the items recognized as non-defective in the regular inspection process and not consumable until the end of the regular inspection process. This process incurs screening cost per item $u$. According to Figure 1, the special inspection process time is $t_{2}-t_{1}$. After the end of the special inspection process, the non-defective items are sold as a batch to waiting customers. It causes an instantaneous reduction in inventory level $\left(B_{2}\right)$. The selling prices of non-defective and defective items per unit are denoted by $S$ and $V$, respectively.

Figure 2 depicts the effect of the regular and special inspection processes on inventory flow.

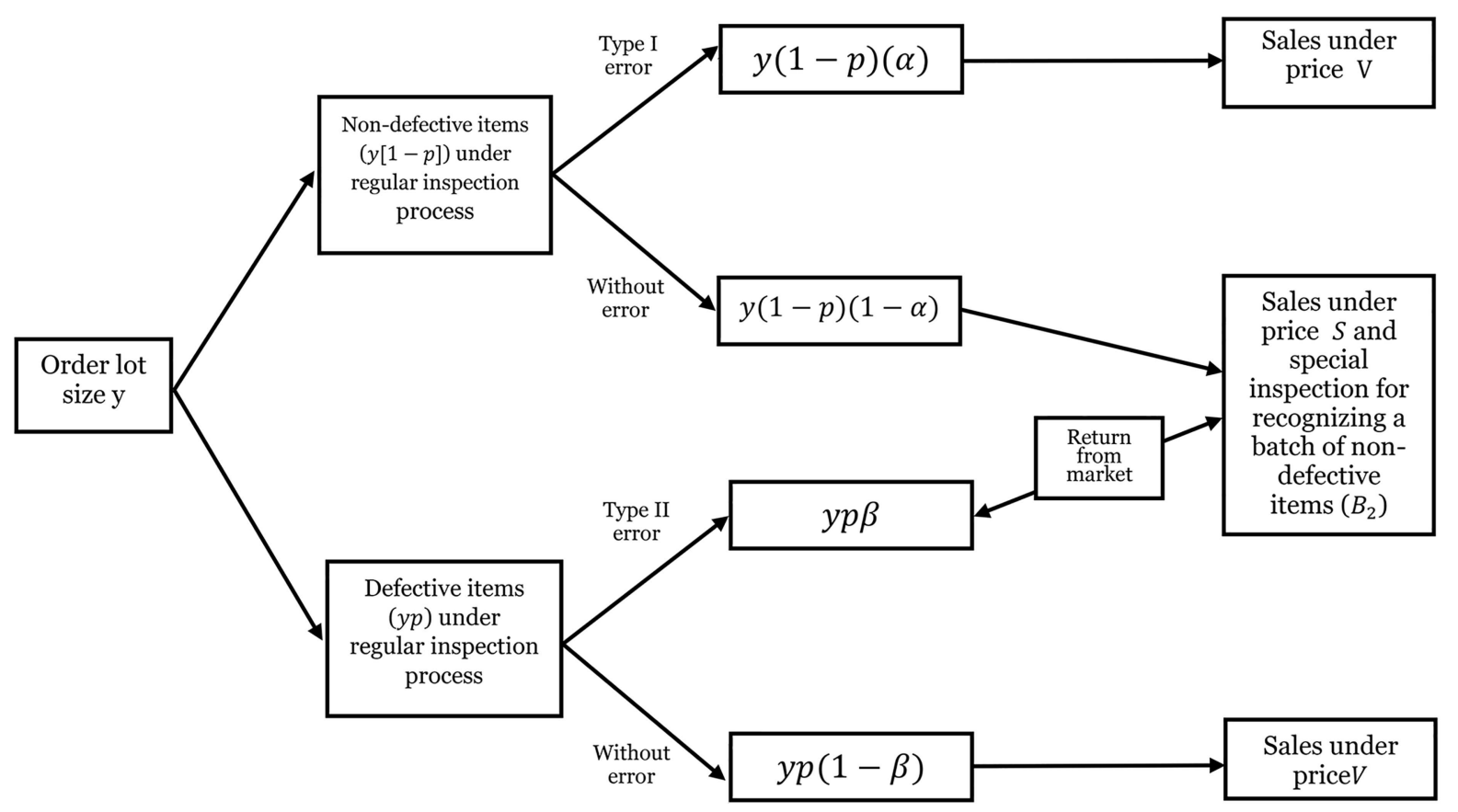

Figure 2. Effect of regular and special inspection processes on inventory flow. 
Let us define $t_{3}$ as the maximum value of time that the special inspection process can finish. In other words, $t_{3}$ denotes the maximum value of $t_{2}$. Moreover, let us define $t_{L}$ as the remaining time, at the time, till end of inventory cycle length, i.e., $t_{3}+t_{L}=T$. As it is obvious, the proportion of non-defective items to defective items at any moment of special inspection process is Ratio $=\frac{y(1-p)(1-\alpha)}{y p \beta}$. At time $t_{3}$, we have $B_{2}$ number of non-defective items and then, according to Ratio, the number of the remaining items $D_{L}$ is calculated as follows:

$$
\begin{aligned}
& \frac{y(1-p)(1-\alpha)}{y p \beta}=\frac{B_{2}}{D_{L}} \Rightarrow \\
& D_{L}=\frac{B_{2} p \beta}{(1-p)(1-\alpha)} .
\end{aligned}
$$

After finishing the special inspection process at time $t_{3}$, the time that takes to consume $D_{L}$ items, i.e., $t_{L}$, under demand rate $D$ can be computed as follows:

$$
t_{L}=\frac{y p^{2} \beta^{2}}{(1-\alpha)(1-p)}
$$

By using $t_{L}$ and knowing that $t_{3}+t_{L}=T$, we can conclude that:

$$
t_{3}=\frac{y\left[(1-\alpha)^{2}(1-p)^{2}-D p^{2} \beta^{2}\right]}{D(1-\alpha)(1-p)} .
$$

The main purpose of this section is to determine the order size which optimizes the total profit per unit time. To do so, we calculate the total revenue and cost functions for one cycle of the proposed inventory problem. The revenues of one cycle, denoted by $T R$, represent the sum of sales of non-defective items, sales of recognized defective items, and sales of returned defective items. Therefore, we can write total revenue $T R$ as follows:

$$
\begin{aligned}
T R(y)= & S y(1-p)(1-\alpha)+V[y(1-p)(\alpha) \\
& +y p(1-\beta)+y p \beta] .
\end{aligned}
$$

The total cost of the proposed inventory system is the sum of the procurement cost, the total inspection cost, the inspection error cost, the holding cost, and the waiting cost. The procurement cost $P C$ equals the sum of ordering and purchasing costs as follows:

$$
P C=k+c y,
$$

where $k$ indicates the fixed ordering cost and $c$ denotes the purchasing cost of items per unit. The total inspection cost per cycle TIC equals the sum of regular inspection cost and special inspection cost. As discussed before, every item must pass through the regular inspection process, while the special inspection seeks to recognize $B_{2}$ non-defective items. Therefore, $T I C$ can be computed as follows:

$$
T I C=d y+u y p \beta,
$$

where $d$ and $u$ are the regular and special inspection costs per unit, respectively. The inspection error cost $I E C$ consists of the cost incurred by the reject cost of non-defective items due to type-I error and the cost incurred by the acceptance cost of defective items due to type-II error. Considering these costs, IEC is formulated as follows:

$$
I E C=c_{r} y(1-p)(\alpha)+c_{a} y p \beta,
$$

where $c_{r}$ is the reject cost of non-defective items per unit and $c_{a}$ is the acceptance cost of defective items per unit. The holding cost per cycle includes the holding cost of non-defective items, the holding cost of items recognized as defective, and the holding cost of the returned items. Then, $H C$ can be calculated as follows:

$$
\begin{aligned}
H C= & h\left\{\frac{y^{2}}{x}[(1-p) \alpha+p(1-\beta)]+t_{2} y p \beta\right. \\
& +\frac{y^{2}(1-p)^{2}(1-\alpha)^{2}}{2 D} \\
& \left.+\frac{y^{2} p \beta(1-p)(1-\alpha)}{2 w D}\right\},
\end{aligned}
$$

where $h$ is the holding cost of items per unit per unit of time. The waiting cost per cycle $W C$ is related to the customers that return defective items which are recognized as non-defective and have to wait until the end of the special inspection process to receive nondefective items. This cost is calculated as follows:

$$
W C=\frac{\pi B_{2} T}{2},
$$

which can be simplified by substituting $B_{2}$ and $T$ to:

$$
\begin{aligned}
W C & =\frac{\pi}{2}(y p \beta)\left(\frac{y(1-p)(1-\alpha)}{D}\right) \\
& =\frac{\pi y^{2} p \beta(1-p)(1-\alpha)}{D} .
\end{aligned}
$$

The total cost $T C$ is obtained by summing the procurement cost, the total inspection cost, the inspection error cost, the holding cost, and the waiting cost as follows: 


$$
\begin{aligned}
T C= & k+c y+d y+u y p \beta+c_{r} y(1-p)(\alpha) \\
& +c_{a} y p \beta+\frac{h y^{2} \alpha(1-p)}{x}+\frac{h y^{2} p(1-\beta)}{x} \\
& +h t_{2} y p \beta+\frac{h y^{2}(1-p)^{2}(1-\alpha)^{2}}{2 D} \\
& +\frac{h y^{2} p \beta(1-p)(1-\alpha)}{2 w D} \\
& +\frac{\pi y^{2} p \beta(1-p)(1-\alpha)}{D} .
\end{aligned}
$$

Now, two different cases are considered in terms of special inspection time period. Case 1 is considered where the special inspection process time is negligible and assumed zero. In this case, the special inspection cost is high due to high fixed costs, while there is no holding cost for items from the special inspection process. Case 2 is considered when the special inspection time is maximum; in this case, the special inspection cost is less than that in Case 1; however, the items in the special inspection process have a high holding cost. Two cases are discussed in detail in the sequel:

\section{Case 1: $t_{2}=t_{1}$}

In this section, we customize the presented general model to a case in which the special inspection process time is negligible $\left(t_{2}=t_{1}\right)$ and the special inspection cost per unit is higher than the regular inspection cost $u=u_{1}\left(u_{1}>d\right)$. By substituting the amounts of $t_{2}$ with $y / x$ and $u$ with $u_{1}$ in $T C$ and then, subtracting the total costs of a cycle from the total revenues of a cycle, the total profit of a cycle $T P(y)$ is obtained as follows:

$$
\begin{aligned}
T P(y)= & T R-T C=S y(1-p)(1-\alpha) \\
& +V y(1-p) \alpha+V y p(1-\beta)+V y p \beta \\
& -k-C y-d y-u_{1} y p \beta-c_{r} y(1-p)(\alpha) \\
& -c_{a} y p \beta-\frac{h y^{2}(1-p) \alpha}{x}-\frac{h y^{2} p(1-\beta)}{x} \\
& -\frac{h y^{2} p \beta}{x}-\frac{h y^{2}(1-p)^{2}(1-\alpha)^{2}}{2 D} \\
& -\frac{h y^{2} p \beta(1-p)(1-\alpha)}{2 w D} \\
& -\frac{\pi y^{2} p \beta(1-p)(1-\alpha)}{D} .
\end{aligned}
$$

Since $p, \alpha$, and $\beta$ are random variables with a known probability density function based on renewal reward theorem, we can conclude that the total profit per unit time is calculated as follows:

$$
E[T P U(y)]=\frac{E[T P(y)]}{E[T]} .
$$

By substituting total profit $T P(y)$ and cycle length $T$ into $E[T P U(y)]$, it can be re-written as follows:

$$
\begin{aligned}
E[T P U & (y)]=S D+\frac{V D E[\alpha]}{E[1-\alpha]}+\frac{V D E[p] E[1-\beta]}{E[1-p] E[1-\alpha]} \\
+ & \frac{V D E[p] E[\beta]}{E[1-p] E[1-\alpha]}-\frac{K D}{y E[1-p] E[1-\alpha]} \\
& -\frac{C D}{E[1-p] E[1-\alpha]}-\frac{d D}{E[1-p] E[1-\alpha]} \\
& -\frac{u_{1} D E[p] E[\beta]}{E[1-p] E[1-\alpha]}-\frac{c_{r} D E[\alpha]}{E[1-\alpha]} \\
& -\frac{c_{a} D E[p] E[\beta]}{E[1-p] E[1-\alpha]}-\frac{h y D E[\alpha]}{x E[1-\alpha]} \\
- & \frac{h y D E[p] E[1-\beta]}{x E[1-p] E[1-\alpha]}-\frac{h y D E[p] E[\beta]}{x E[1-p] E[1-\alpha]} \\
& -\frac{h y E\left[(1-p)^{2}\right] E\left[(1-\alpha)^{2}\right]}{2 E[1-p] E[1-\alpha]} \\
- & \frac{h y E[p] E[\beta]}{2 w}-\pi y E[p] E[\beta] .
\end{aligned}
$$

To determine the order size that maximizes the total profit per unit time, the first derivative and the second derivative of $E[T P U(y)]$ are derived as follows:

$$
\begin{gathered}
\frac{\partial E[T P U(y)]}{\partial y}=\frac{K D}{y^{2} E[1-p] E[1-\alpha]}-\frac{h D E[\alpha]}{x E[1-\alpha]} \\
-\frac{h D E[p] E[1-\beta]}{x E[1-p] E[1-\alpha]}-\frac{h D E[p] E[\beta]}{x E[1-p] E[1-\alpha]} \\
-\frac{h E\left[(1-p)^{2}\right] E\left[(1-\alpha)^{2}\right]}{2 E[1-p] E[1-\alpha]}-\frac{h E[p] E[\beta]}{2 w} \\
-\pi E[p] E[\beta], \\
\frac{\partial^{2} E[T P U(y)]}{\partial y^{2}}=-\frac{2 K D}{y E[1-p] E[1-\alpha]} .
\end{gathered}
$$

Since the second derivative of $E[T P U(y)]$ is always smaller than zero, $E[T P U(y)]$ is a concave function and has a unique and global optimum that can be obtained by setting the first derivative of $E[T P U(y)]$ to zero (see Eq. (26) in Box I). If we relax the conditions that we used for designing our proposed inventory problem, i.e., 


$$
\begin{aligned}
& y_{1}^{*}= \\
& \sqrt{\frac{\left.\frac{h D E[\alpha]}{x E[1-\alpha]}+\frac{h D E[p] E[1-\beta]}{x E[1-p] E[1-\alpha]}+\frac{h D E[p] E[\beta]}{x E[1-p] E[1-\alpha]}+\frac{h E\left[(1-p)^{2}\right] E\left[(1-\alpha)^{2}\right]}{2 E[1-p] E[1-\alpha]}+\frac{h E[p] E[\beta]}{2 w}+\pi E[p] E[\beta]\right][E[1-p] E[1-\alpha]]}{[.}} .
\end{aligned}
$$

Box I

there is no defective items $(p=0)$ with no inspection errors, then the optimal order size is reduced to the optimal order size for the classic EOQ model, i.e., $y_{1}^{*}=y_{E O Q}^{*}=\sqrt{2 k D / h}$. This verifies the expressions derived in the model (Case 1 ).

\section{Case 2: $t_{2}=t_{3}$}

In this section, we customize the general model presented before to a case in which the special inspection time is maximum, i.e.:

$$
t_{2}=\frac{y\left[(1-\alpha)^{2}(1-p)^{2}-D p^{2} \beta^{2}\right]}{D(1-\alpha)(1-p)} .
$$

The special inspection cost is $u=u_{2}\left(u_{2} \leq u_{1}\right)$. By substituting the amounts of $t_{2}$ and $u$ in $T C$ and, then, subtracting the total costs of a cycle from the total revenues of a cycle, the total profit of a cycle $T P(y)$ would be:

$$
\begin{aligned}
T P(y)= & T R(y)-T C(y)=S y(1-p)(1-\alpha) \\
& +V y(1-p) \alpha+V y p(1-\beta)+V y p \beta \\
& -k-C y-d y-u_{2} y p \beta-c_{r} y(1-p)(\alpha)
\end{aligned}
$$

$$
\begin{aligned}
& -c_{a} y p \beta-\frac{h y^{2}(1-p) \alpha}{x}-\frac{h y^{2} p(1-\beta)}{x} \\
& -\frac{h y^{2} p \beta\left[(1-\alpha)^{2}(1-p)^{2}-D p^{2} \beta^{2}\right]}{D(1-\alpha)(1-p)} \\
& -\frac{h y^{2}(1-p)^{2}(1-\alpha)^{2}}{2 D} \\
& -\frac{h y^{2} p \beta(1-p)(1-\alpha)}{2 w D} \\
& -\frac{\pi y^{2} p \beta(1-p)(1-\alpha)}{D} .
\end{aligned}
$$

Therefore, using renewal reward theorem, $E[T P U(y)]$ is given by Eq. (28) as shown in Box II. To achieve the optimal order size, the first and the second derivatives of $E[T P U(y)]$ are obtained by Eqs. (29) and (30) as shown in Box III.

As can be seen, the second derivative of $E[T P U(y)]$ is always smaller than zero; thus, $E[T P U(y)]$ is a concave function. For an optimal order size that maximizes the total profit per unit time, there is a unique and global solution that can

$$
\begin{aligned}
E[T P U(y)]= & S D+\frac{V D E[\alpha]}{E[1-\alpha]}+\frac{V D E[p] E[1-\beta]}{E[1-p] E[1-\alpha]}+\frac{V D E[p] E[\beta]}{E[1-p] E[1-\alpha]}-\frac{K D}{y E[1-p] E[1-\alpha]} \\
& -\frac{C D}{E[1-p] E[1-\alpha]}-\frac{d D}{E[1-p] E[1-\alpha]}-\frac{u_{1} D E[p] E[\beta]}{E[1-p] E[1-\alpha]}-\frac{c_{r} D E[\alpha]}{E[1-\alpha]}-\frac{c_{a} D E[p] E[\beta]}{E[1-p] E[1-\alpha]} \\
& -\frac{h y D E[\alpha]}{x E[1-\alpha]}-\frac{h y D E[p] E[1-\beta]}{x E[1-p] E[1-\alpha]} \\
& -\frac{h y E[p] E[\beta] E\left[\frac{1}{1-p}\right] E\left[\frac{1}{1-\alpha}\right]\left\{E\left[(1-\alpha)^{2}\right] E\left[(1-p)^{2}\right]-D E\left[p^{2}\right] E\left[\beta^{2}\right]\right\}}{E[1-p] E[1-\alpha]} \\
& -\frac{h y E\left[(1-p)^{2}\right] E\left[(1-\alpha)^{2}\right]}{2 E[1-p] E[1-\alpha]}-\frac{h y E[p] E[\beta]}{2 w}-\pi y E[p] E[\beta] .
\end{aligned}
$$




$$
\begin{aligned}
\frac{\partial E[T P U(y)]}{\partial y}= & \frac{K D}{y^{2} E[1-p] E[1-\alpha]}-\frac{h D E[\alpha]}{x E[1-\alpha]}-\frac{h D E[p] E[1-\beta]}{x E[1-p] E[1-\alpha]} \\
- & \frac{h E[p] E[\beta] E\left[\frac{1}{1-p}\right] E\left[\frac{1}{1-\alpha}\right]\left\{E\left[(1-\alpha)^{2}\right] E\left[(1-p)^{2}\right]-D E\left[p^{2}\right] E\left[\beta^{2}\right]\right\}}{E[1-p] E[1-\alpha]} \\
- & \frac{h E\left[(1-p)^{2}\right] E\left[(1-\alpha)^{2}\right]}{2 E[1-p] E[1-\alpha]}-\frac{h E[p] E[\beta]}{2 w}-\pi E[p] E[\beta] \\
\frac{\partial^{2} E[T P U(y)]}{\partial y^{2}} & =-\frac{2 K D}{y E[1-p] E[1-\alpha]}
\end{aligned}
$$

Box III

$$
\begin{aligned}
& y_{2}^{*}= \\
& \sqrt{\frac{\frac{h D E[\alpha]}{x E[1-\alpha]}+\frac{h D E[p] E[1-\beta]}{x E[1-p] E[1-\alpha]}+\frac{h E[p] E[\beta] E\left[\frac{1}{1-p}\right] E\left[\frac{1}{1-\alpha}\right]\left\{E\left[(1-\alpha)^{2}\right] E\left[(1-p)^{2}\right]-D E\left[p^{2}\right] E\left[\beta^{2}\right]\right\}}{E[1-p] E[1-\alpha]}}{2}} \\
& \sqrt{\left.+\frac{h E\left[(1-p)^{2}\right] E\left[(1-\alpha)^{2}\right]}{2 E[1-p] E[1-\alpha]}+\frac{h E[p] E[\beta]}{2 w}+\pi E[p] E[\beta]\right][E[1-p] E[1-\alpha]]}
\end{aligned}
$$

Box IV

be obtained by setting the first derivative to zero (see Eq. (31) shown in Box IV). Similar to Case 1, if we relax the conditions that we used for designing our proposed inventory problem, then the optimal order size is reduced to the optimal order size for the classic EOQ model, i.e., $y_{2}^{*}=y_{E O Q}^{*}=\sqrt{2 K D / h}$. This verifies the expressions derived in the model (Case 2).

\section{Experimental results}

In this section, a numerical example is provided for investigating the application of the proposed problem in two cases. The optimal order sizes are obtained and, then, optimal expected values for the total profit per unit time of Cases 1 and 2 are calculated separately. Then, two cases are compared to select the more profitable one. Finally, we execute a sensitivity analysis for the main parameters of the problem and discuss the results.

\subsection{Numerical example}

This section presents a numerical example for comparing the application of two proposed models in terms of total profit per unit time. Numerical examples' parameters are: $D=100000$ units per unit time, $k=\$ 160$ per order, $c=\$ 30$ per unit, $h=\$ 4$ per unit per unit of time, $S=\$ 45$ per unit, $V=\$ 20$ per unit, $x=400000$ per unit time, $d=\$ 1$ per unit, $c_{a}=\$ 200$ per unit, $c_{r}=\$ 30$ per unit, $u_{1}=\$ 16$ per unit, $u_{2}=\$ 8$ per unit, $\pi=\$ 12$ per unit per unit of time, and $w=8$ per cycle:

$$
\begin{aligned}
& f(p)=\left\{\begin{array}{ll}
\frac{1}{b-a} & a<p<b \\
0 & O . W .
\end{array},\right. \\
& f(\alpha)=\left\{\begin{array}{ll}
\frac{1}{d-c} & c<\alpha<d \\
0 & O . W .
\end{array},\right. \\
& f(\beta)= \begin{cases}\frac{1}{f-e} & e<\beta<f \\
0 & \text { O.W. }\end{cases}
\end{aligned}
$$

Table 2 presents the optimal order size and the expected profit per unit time for Cases 1 and 2 . Furthermore, it shows the expected revenues and costs per unit time separately. Optimal order size for 
Table 2. The optimal order size and total profit per unit time for two cases.

\begin{tabular}{lcccc}
\hline \multicolumn{1}{c}{ Parameters } & Case 2 & Case 1 & Case 2-Case 1 & \% \\
\hline$y^{*}$ & 2722.49 & 2724.05 & - & - \\
\hline$E[T R U(y)]$ & 4625850.34 & 4625850.34 & 0.00 & 0.00 \\
Sales (non-defective items) & 4500000 & 4500000 & 0.00 & 0.00 \\
Sales (recognized defective items) & 124149.66 & 124149.66 & 0.00 & 0.00 \\
Sales (returned defective items) & 1700.68 & 1700.68 & 0.00 & 0.00 \\
\hline$E[T C U(y)]$ & 3386473.17 & 3387146.29 & -673.12 & -0.0198 \\
Procurement & 3195022.30 & 3195018.72 & 3.58 & 0.0001 \\
Regular inspection & 106292.51 & 106292.51 & 0.00 & 0.00 \\
Special inspection & 680.27 & 1360.54 & -680.27 & -50 \\
Inspection errors & 78231.29 & 78231.29 & 0.00 & 0.00 \\
Holding & 6220.65 & 6217.06 & 3.59 & 0.0577 \\
Waiting & 26.13 & 26.15 & -0.02 & -0.0572 \\
\hline$E[T P U(y)]$ & 1239377.17 & 1238704.05 & 673.12 & 0.0547 \\
\hline
\end{tabular}

Cases 1 and 2 is calculated. The expected profit per unit time for Cases 1 and 2 is also achieved. Moreover, the last column of the table shows the relative percentage deviation between Cases 1 and 2 by $\%=($ Case $2-$ Case 1$) /$ Case $1 * 100$. Case 2 gains $\$ 673.12$ profit per unit time more than Case 1 . It is also obvious that both cases have equal revenues and the profitability in Case 2 corresponds to its lower cost value. According to the model expression section, Case 1 model has less holding cost than Case 2 model; in return, Case 2 model is less expensive in the special inspection section. According to the results presented in Table 2, Case 1 saves $\$ 3.59$ per unit time in terms of holding cost, while Case 2 has $\$ 680.27$ per unit time less cost in terms of the special inspection cost. It is noteworthy that Case 1 maintains a better standing than Case 2 in terms of procurement cost, but its excellence is so low that it does not affect the profit per unit time.

Figure 3 shows the expected profit per unit time for Cases 1 and 2 as a function of order size. This figure demonstrates the concavity of total profit per unit time

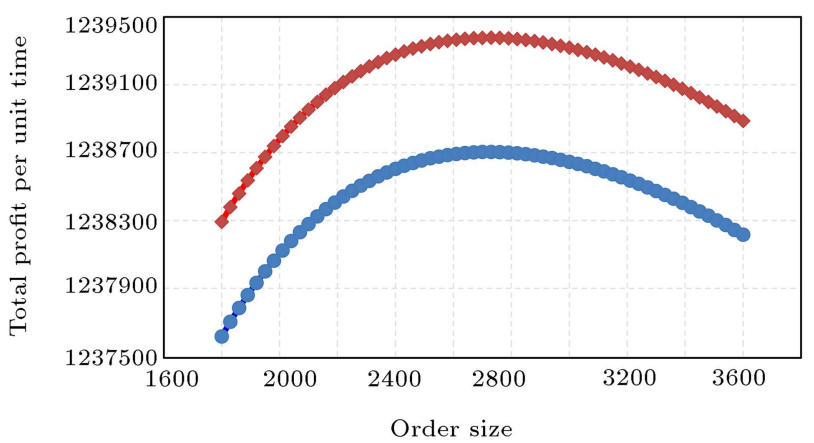

Figure 3. The comparison of the total profit per unit time for two cases. for both cases graphically. According to this figure, we see that considering an order size larger than optimal order size, in both models, the profit per unit time decreases with a smaller slope than considering the order size smaller than the optimal order size. When order size is 2400 , the profit per unit time decreases by $0.008 \%$ with respect to the optimal value, while at order size 3000 , the profit per unit time decreases by $0.004 \%$ with respect to the optimal value. Also, it is obvious that Case 2 yields a better profit for all the ranges and amounts close to the optimal order size of both models. Figure 3 confirms that Case 2 gains $0.05 \%$ profit more than Case 1 for every value of order size. Since results imply that Case 2 is more profitable than Case 1, the sensitivity analysis will be carried out for this case in the sequel.

\subsection{Sensitivity analysis}

In this section, an analysis of sensitivity is performed for different numbers of the main parameters, the percentage of defective items $p$, the probability of typeI error $\propto$, probability of type-II error $\beta$, the number of discounted sales per cycle $w$, the holding cost per unit per unit of time $h$, the special inspection cost per unit $u_{2}$, the waiting cost per unit per unit of time $\pi$, and the demand rate per unit time $D$ in Case 2 of the problem. For each parameter, the number of parameters changes in the range of $-50 \%$ to $+50 \%$, while the remaining parameters are fixed and, then, the effects of changes in parameter on profits, revenues, and costs are recorded. For parameters of the same nature and scale, the analysis is depicted on a single plot. Table 3 shows the variation of total profit per unit time with respect to the changes of defective items percentage $p$. Because $f(p)$ follows a uniform distribution with the parameters $a$ and $b$, in order to change $E(p)$, we consider different 
Table 3. Sensitivity analysis of the probability of an item being defective $p$.

\begin{tabular}{|c|c|c|c|c|c|c|c|c|c|c|}
\hline$a$ & 0.01 & 0.01 & 0.01 & 0.01 & 0.01 & 0.01 & 0.01 & 0.01 & 0.01 & \multirow{4}{*}{ Change } \\
\hline$b$ & 0.03 & 0.04 & 0.05 & 0.06 & 0.07 & 0.08 & 0.09 & 0.10 & 0.11 & \\
\hline$E(p)$ & 0.02 & 0.03 & 0.03 & 0.04 & 0.04 & 0.05 & 0.05 & 0.06 & 0.06 & \\
\hline$\%$ & -50.00 & -37.50 & -25.00 & -12.50 & 0.00 & 12.50 & 25.00 & 37.50 & 50.00 & \\
\hline$y_{2}^{*}$ & 2372.77 & 2523.56 & 2614.01 & 2676.06 & 2722.49 & 2759.39 & 2790.06 & 2816.43 & 2839.73 & + \\
\hline$E[T R U(y)]$ & 4582465.64 & 4593144.95 & 4603934.36 & 4614835.57 & 4625850.34 & 4636980.45 & 4648227.71 & 4659594.00 & 4671081.20 & + \\
\hline $\begin{array}{l}\text { Sales (non- } \\
\text { defective items) }\end{array}$ & 4500000.00 & 4500000.00 & 4500000.00 & 4500000.00 & 4500000.00 & 4500000.00 & 4500000.00 & 4500000.00 & 4500000.00 & 0.00 \\
\hline $\begin{array}{l}\text { Sales (defective } \\
\text { recognized items) }\end{array}$ & 81632.65 & 92098.38 & 102672.00 & 113355.19 & 124149.66 & 135057.16 & 146079.48 & 157218.44 & 168475.90 & + \\
\hline $\begin{array}{l}\text { Sales (items } \\
\text { returned from market) }\end{array}$ & 832.99 & 1046.57 & 1262.36 & 1480.38 & 1700.68 & 1923.28 & 2148.23 & 2375.55 & 2605.30 & + \\
\hline$E[T C U(y)]$ & 3311751.71 & 3329754.56 & 3348329.21 & 3367260.09 & 3386473.17 & 3405937.37 & 3425638.35 & 3445569.48 & 3465728.03 & + \\
\hline Procurement & 3130719.67 & 3146352.95 & 3162340.50 & 3178575.59 & 3195022.30 & 3211666.19 & 3228501.24 & 3245525.26 & 3262738.09 & + \\
\hline Regular inspection & 104123.28 & 104657.25 & 105196.72 & 105741.78 & 106292.52 & 106849.02 & 107411.39 & 107979.70 & 108554.06 & + \\
\hline Special inspection & 333.19 & 418.63 & 504.94 & 592.15 & 680.27 & 769.31 & 859.29 & 950.22 & 1042.12 & + \\
\hline Inspection errors & 69554.35 & 71690.21 & 73848.10 & 76028.34 & 78231.29 & 80457.31 & 82706.77 & 84980.02 & 87277.46 & + \\
\hline Holding & 7009.82 & 6620.38 & 6420.14 & 6299.75 & 6220.65 & 6165.72 & 6126.19 & 6097.09 & 6075.40 & - \\
\hline Waiting & 11.39 & 15.14 & 18.82 & 22.48 & 26.14 & 29.80 & 33.48 & 37.18 & 40.89 & + \\
\hline$E[T P U(y)]$ & 1270713.93 & 1263390.39 & 1255605.14 & 1247575.48 & 1239377.17 & 1231043.08 & 1222589.36 & 1214024.52 & 1205353.16 & - \\
\hline$\%$ & 2.53 & 1.94 & 1.31 & 0.66 & 0.00 & -0.67 & -1.35 & -2.05 & -2.75 & - \\
\hline
\end{tabular}

Table 4. Sensitivity analysis of the type-I error probability $\alpha$.

\begin{tabular}{|c|c|c|c|c|c|c|c|c|c|c|}
\hline$c$ & 0.0000 & 0.0025 & 0.0050 & 0.0075 & 0.0100 & 0.0125 & 0.0150 & 0.0175 & 0.0200 & \\
\hline$d$ & 0.0200 & 0.0225 & 0.0250 & 0.0275 & 0.0300 & 0.0325 & 0.0350 & 0.0375 & 0.0400 & \\
\hline$E(\alpha)$ & 0.0100 & 0.0125 & 0.0150 & 0.0175 & 0.0200 & 0.0225 & 0.0250 & 0.0275 & 0.0300 & Change \\
\hline$\%$ & -50.00 & -37.50 & -25.00 & -12.50 & 0.00 & 12.50 & 25.00 & 37.50 & 50.00 & \\
\hline$y_{2}^{*}$ & 2701.69 & 2706.87 & 2712.06 & 2717.27 & 2722.49 & 2727.72 & 2732.96 & 2738.22 & 2743.49 & + \\
\hline$E[T R U(y)]$ & 4604377.10 & 4609704.64 & 4615059.22 & 4620441.05 & 4625850.34 & 4631287.30 & 4636752.14 & 4642245.07 & 4647766.32 & + \\
\hline $\begin{array}{l}\text { Sales (non- } \\
\text { defective items) }\end{array}$ & 4500000.00 & 4500000.00 & 4500000.00 & 4500000.00 & 4500000.00 & 4500000.00 & 4500000.00 & 4500000.00 & 4500000.00 & 0.00 \\
\hline $\begin{array}{l}\text { Sales (defective } \\
\text { recognized items) }\end{array}$ & 102693.60 & 108016.88 & 113367.17 & 118744.70 & 124149.66 & 129582.27 & 135042.74 & 140531.28 & 146048.11 & + \\
\hline $\begin{array}{l}\text { Sales (items } \\
\text { returned from market) }\end{array}$ & 1683.50 & 1687.76 & 1692.05 & 1696.35 & 1700.68 & 1705.03 & 1709.40 & 1713.80 & 1718.21 & + \\
\hline$E[T C U(y)]$ & 3322058.53 & 3338039.83 & 3354102.30 & 3370246.53 & 3386473.17 & 3402782.84 & 3419176.19 & 3435653.85 & 3452216.48 & + \\
\hline Procurement & 3162796.94 & 3170792.07 & 3178827.80 & 3186904.44 & 3195022.30 & 3203181.70 & 3211382.96 & 3219626.41 & 3227912.36 & + \\
\hline Regular inspection & 105218.86 & 105485.23 & 105752.96 & 106022.05 & 106292.52 & 106564.36 & 106837.61 & 107112.25 & 107388.32 & + \\
\hline Special inspection & 673.40 & 675.11 & 676.82 & 678.54 & 680.27 & 682.01 & 683.76 & 685.52 & 687.29 & + \\
\hline Inspection errors & 47138.05 & 54852.32 & 62605.75 & 70398.64 & 78231.29 & 86104.01 & 94017.09 & 101970.87 & 109965.64 & + \\
\hline Holding & 6205.35 & 6209.12 & 6212.93 & 6216.77 & 6220.65 & 6224.57 & 6228.52 & 6232.51 & 6236.54 & + \\
\hline Waiting & 25.94 & 25.99 & 26.04 & 26.09 & 26.14 & 26.19 & 26.24 & 26.29 & 26.34 & + \\
\hline$E[T P U(y)]$ & 1282318.58 & 1271664.81 & 1260956.93 & 1250194.52 & 1239377.17 & 1228504.46 & 1217575.95 & 1206591.23 & 1195549.85 & - \\
\hline$\%$ & 3.46 & 2.61 & 1.74 & 0.87 & 0.00 & -0.88 & -1.76 & -2.65 & -3.54 & - \\
\hline
\end{tabular}

values for $b$ while leaving the remaining parameters unchanged. The optimal order size in the range of $p$ has increased 466.96 unit, which can be concluded that by increasing the defective items percentage $p$, the order size increases such that we can still satisfy the demand and no shortage occurs. As logical reasoning also confirms, by increasing parameter $p$, total profit per unit time should decrease. Table 3 indicates that the total revenues and total costs per unit time are increasing; however, increase in costs is higher than the revenues. In the changes range, the total revenue per unit time has increased for $\$ 88615.56$ and total costs per unit time have increased for $\$ 153976.32$ which ultimately leads to $\$ 65360.76$ in total profit per unit time. The reason is that the revenue is generated upon increasing the sales of the items recognized as defective items (returning items from the market), but increase in the percentage of defective items will increase procurement costs, regular inspections costs, special inspection costs, inspection errors costs, and waiting costs.

Table 4 shows the profit variation according to variations in type-I error probability $\alpha$. Also, $f(\alpha)$ follows the uniform distribution with parameters $c$ 
Table 5. Sensitivity analysis of the type-II error probability $\beta$.

\begin{tabular}{|c|c|c|c|c|c|c|c|c|c|c|}
\hline$e$ & 0.0000 & 0.0025 & 0.0050 & 0.0075 & 0.0100 & 0.0125 & 0.0150 & 0.0175 & 0.0200 & \multirow{4}{*}{ Change } \\
\hline$f$ & 0.0200 & 0.0225 & 0.0250 & 0.0275 & 0.0300 & 0.0325 & 0.0350 & 0.0375 & 0.0400 & \\
\hline$E(\beta)$ & 0.0100 & 0.0125 & 0.0150 & 0.0175 & 0.0200 & 0.0225 & 0.0250 & 0.0275 & 0.0300 & \\
\hline$\%$ & -50.00 & -37.50 & -25.00 & -12.50 & 0.00 & 12.50 & 25.00 & 37.50 & 50.00 & \\
\hline$y_{2}^{*}$ & 2726.12 & 2725.19 & 2724.28 & 2723.38 & 2722.49 & 2721.61 & 2720.76 & 2719.93 & 2719.11 & - \\
\hline$E[T R U(y)]$ & 4625850.34 & 4625850.34 & 4625850.34 & 4625850.34 & $462585 \quad 0.34$ & 4625850.34 & 4625850.34 & 4625850.34 & 4625850.34 & 0.00 \\
\hline $\begin{array}{l}\text { Sales (non- } \\
\text { defective items) }\end{array}$ & 4500000.00 & 4500000.00 & 4500000.00 & 4500000.00 & 4500000.00 & 4500000.00 & 4500000.00 & 4500000.00 & 4500000.00 & 0.00 \\
\hline $\begin{array}{l}\text { Sales (defective } \\
\text { recognized items) }\end{array}$ & 125000.00 & 124787.41 & 124574.83 & 124362.24 & 124149.66 & 123937.07 & 123724.49 & 123511.90 & 123299.32 & - \\
\hline $\begin{array}{l}\text { Sales (items } \\
\text { returned from market) }\end{array}$ & 850.34 & 1062.93 & 1275.51 & 1488.10 & 1700.68 & 1913.27 & 2125.85 & 2338.44 & 2551.02 & + \\
\hline$E[T C U(y)]$ & 3377612.99 & 3379828.11 & 3382043.19 & 3384258.21 & 3386473.17 & 3388688.06 & 3390902.87 & 3393117.59 & 3395332.21 & + \\
\hline Procurement & 3195013.98 & 3195016.10 & 3195018.19 & 3195020.26 & 3195022.30 & 3195024.30 & 3195026.26 & 3195028.18 & 3195030.05 & + \\
\hline Regular inspection & 106292.52 & 106292.52 & 106292.52 & 106292.52 & 106292.52 & 106292.52 & 106292.52 & 106292.52 & 106292.52 & 0.00 \\
\hline Special inspection & 340.14 & 425.17 & 510.20 & 595.24 & 680.27 & 765.31 & 850.34 & 935.37 & 1020.41 & + \\
\hline Inspection errors & 69727.89 & 71853.74 & 73979.59 & 76105.44 & 78231.29 & 80357.14 & 82482.99 & 84608.84 & 86734.69 & + \\
\hline Holding & 6225.38 & 6224.23 & 6223.07 & 6221.87 & 6220.65 & 6219.40 & 6218.10 & 6216.77 & 6215.39 & - \\
\hline Waiting & 13.09 & 16.35 & 19.61 & 22.88 & 26.14 & 29.39 & 32.65 & 35.90 & 39.16 & + \\
\hline$E[T P U(y)]$ & 1248237.35 & 1246022.23 & 1243807.15 & 1241592.13 & 1239377.17 & 1237162.28 & 1234947.47 & 1232732.75 & 1230518.13 & - \\
\hline$\%$ & 0.71 & 0.54 & 0.36 & 0.18 & 0.00 & -0.18 & -0.36 & -0.54 & -0.71 & - \\
\hline
\end{tabular}

and $d$. We adjust $c$ and $d$ such that $E(\alpha)$ changes in the range of $-50 \%$ to $+50 \%$. Also, by increasing $\alpha$, the order size increases too, but has a far less increase than parameter $p$ and only increases 41.8 unit. The total revenues per unit time in the range of $\alpha$ increase as $\$ 43389.22$ and the total costs per unit time increase as $\$ 130157.95$. Costs have grown three times than revenues, causing profit decrease as $\$ 86768.73$ in the range of variations. Loss of greater profit than parameter $p$ occurs for three reasons; first, revenues do not grow as $p$; second, the costs of inspection errors increase with more gradient because of $\alpha$ change; and third is that holding cost decreases with increase in $p$, but increases when $\alpha$ increases.

Table 5 shows the total profit variations per unit time according to the variations of the type-II error probability $\beta$. It is assumed that $f(\beta)$ follows a uniform distribution with the parameters $e$ and $f$, the same as the two previous parameters. Here, the parameters $e$ and $f$ change in such a way that $E(\beta)$ varies according to the desired range. Unlike the parameters of $p$ and $\alpha$, this time with increase in the parameter $\beta$, the optimal order size decreases partially by as much as 7.01 . The total profit per unit time is still inversely proportional to the parameter $\beta$; however, this time, it is less sensitive than the two previous parameters. There are several reasons why this happens. First reason is that the revenue from selling recognized defective items in the range of $\beta$ decreases, while the revenue from sales of returned items from the market increases, and then the total revenue remains unchanged. The second reason is that the total cost per unit time only increases up to

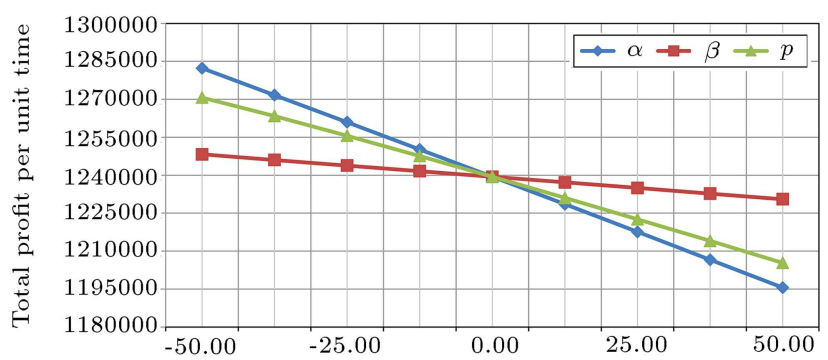

Figure 4. The effect of changes in the parameters $p, \alpha$, and $\beta$ on total profit per unit time.

$\$ 17719.22$, which is less than those of the two previous parameters. The reason for this is the constancy of regular inspection cost and decrease in holding costs. The rest of the costs, although they have grown, in most cases have become more lenient in there increase gradient.

Figure 4 illustrates the variations of total profit per unit time for the parameters $p, \alpha$, and $\beta$ in the range of $-50 \%$ and $50 \%$. Obviously, all three parameters have an inverse relationship with total profit per unit time. The gradient figure for parameter $p$ indicates that the fluctuations in its values will have the greatest effect on the total profit per unit time. Also, with the variations in the parameter $p$, even though it has less effect on earning the profit per unit time, it is almost parallel to the level of the parameter $\alpha$. The total profit per unit time by variations in the parameter $\beta$ in the range of similar variations of the parameters $p$ and $\alpha$ exhibits lower sensitivity. It can be concluded that in our proposed model, controlling 
Table 6. Sensitivity analysis of the cost of rejecting a non-defective item $c_{r}$.

\begin{tabular}{|c|c|c|c|c|c|c|c|c|c|c|}
\hline$c_{r}$ & 15.00 & 18.75 & 22.50 & 26.25 & 30.00 & 33.75 & 37.50 & 41.25 & 45.00 & Chanoe \\
\hline$\%$ & -50.00 & -37.50 & -25.00 & -12.50 & 0.00 & 12.50 & 25.00 & 37.50 & 50.00 & \\
\hline$y_{2}^{*}$ & 2722.49 & 2722.49 & 2722.49 & 2722.49 & 2722.49 & 2722.49 & 2722.49 & 2722.49 & 2722.49 & 0.00 \\
\hline$E[T R U(y)]$ & 4625850.34 & 4625850.34 & 4625850.34 & 4625850.34 & 4625850.34 & 4625850.34 & 4625850.34 & 4625850.34 & 4625850.34 & 0.00 \\
\hline $\begin{array}{l}\text { Sales (non- } \\
\text { defective items) }\end{array}$ & 4500000.00 & 4500000.00 & 4500000.00 & 4500000.00 & 4500000.00 & 4500000.00 & 4500000.00 & 4500000.00 & 4500000.00 & 0.00 \\
\hline $\begin{array}{l}\text { Sales (defective } \\
\text { recognized items) }\end{array}$ & 124149.66 & 124149.66 & 124149.66 & 124149.66 & 124149.66 & 124149.66 & 124149.66 & 124149.66 & 124149.66 & 0.00 \\
\hline $\begin{array}{l}\text { Sales (items } \\
\text { returned from market) }\end{array}$ & 1700.68 & 1700.68 & 1700.68 & 1700.68 & 1700.68 & 1700.68 & 1700.68 & 1700.68 & 1700.68 & 0.00 \\
\hline$E[T C U(y)]$ & 3355860.93 & 3363513.99 & 3371167.05 & 3378820.11 & 3386473.17 & 3394126.23 & 3401779.29 & 3409432.35 & 3417085.42 & + \\
\hline Procurement & 3195022.30 & 3195022.30 & 3195022.30 & 3195022.30 & 3195022.30 & 3195022.30 & 3195022.30 & 3195022.30 & 3195022.30 & 0.00 \\
\hline Regular inspection & 106292.52 & 106292.52 & 106292.52 & 106292.52 & 106292.52 & 106292.52 & 106292.52 & 106292.52 & 106292.52 & 0.00 \\
\hline Special inspection & 680.27 & 680.27 & 680.27 & 680.27 & 680.27 & 680.27 & 680.27 & 680.27 & 680.27 & 0.00 \\
\hline Inspection errors & 47619.05 & 55272.11 & 62925.17 & 70578.23 & 78231.29 & 85884.35 & 93537.41 & 101190.48 & 108843.54 & + \\
\hline Holding & 6220.65 & 6220.65 & 6220.65 & 6220.65 & 6220.65 & 6220.65 & 6220.65 & 6220.65 & 6220.65 & 0.00 \\
\hline Waiting & 26.14 & 26.14 & 26.14 & 26.14 & 26.14 & 26.14 & 26.14 & 26.14 & 26.14 & 0.00 \\
\hline$E[T P U(y)]$ & 1269989.41 & 1262336.35 & 1254683.29 & 1247030.23 & 1239377.17 & 1231724.11 & 1224071.05 & 1216417.99 & 1208764.92 & - \\
\hline$\%$ & 2.47 & 1.85 & 1.23 & 0.62 & 0.00 & -0.62 & -1.23 & -1.85 & -2.47 & - \\
\hline
\end{tabular}

Table 7. Sensitivity analysis of the cost of accepting a defective item $c_{a}$.

\begin{tabular}{|c|c|c|c|c|c|c|c|c|c|c|}
\hline$c_{a}$ & 100.00 & 125.00 & 150.00 & 175.00 & 200.00 & 225.00 & 250.00 & 275.00 & & Chance \\
\hline$\%$ & -50.00 & -37.50 & -25.00 & -12.50 & 0.00 & 12.50 & 25.00 & 37.50 & 50.00 & \\
\hline$y_{2}^{*}$ & 2722.49 & 2722.49 & 2722.49 & 2722.49 & 2722.49 & 2722.49 & 2722.49 & 2722.49 & 2722.49 & 0.00 \\
\hline$E[T R U(y)]$ & 4625850.34 & 4625850.34 & 4625850.34 & 4625850.34 & 4625850.34 & 4625850.34 & 4625850.34 & 4625850.34 & 4625850.34 & 0.00 \\
\hline $\begin{array}{l}\text { Sales (non- } \\
\text { defective items) }\end{array}$ & 4500000.00 & 4500000.00 & 4500000.00 & 4500000.00 & 4500000.00 & 4500000.00 & 4500000.00 & 4500000.00 & 4500000.00 & 0.00 \\
\hline $\begin{array}{l}\text { Sales (defective } \\
\text { recognized items) }\end{array}$ & 124149.66 & 124149.66 & 124149.66 & 124149.66 & 124149.66 & 124149.66 & 124149.66 & 124149.66 & 124149.66 & 0.00 \\
\hline $\begin{array}{l}\text { Sales (items } \\
\text { returned from market) }\end{array}$ & 1700.68 & 1700.68 & 1700.68 & 1700.68 & 1700.68 & 1700.68 & 1700.68 & 1700.68 & 1700.68 & 0.00 \\
\hline$E[T C U(y)]$ & 3377969.77 & 3380095.62 & 3382221.47 & 3384347.32 & 3386473.17 & 3388599.02 & 3390724.87 & 3392850.72 & 3394976.57 & + \\
\hline Procurement & 3195022.30 & 3195022.30 & 3195022.30 & 3195022.30 & 3195022.30 & 3195022.30 & 3195022.30 & 3195022.30 & 3195022.30 & 0.00 \\
\hline Regular inspection & 106292.52 & 106292.52 & 106292.52 & 106292.52 & 106292.52 & 106292.52 & 106292.52 & 106292.52 & 106292.52 & 0.00 \\
\hline Special inspection & 680.27 & 680.27 & 680.27 & 680.27 & 680.27 & 680.27 & 680.27 & 680.27 & 680.27 & 0.00 \\
\hline Inspection errors & 69727.89 & 71853.74 & 73979.59 & 76105.44 & 78231.29 & 80357.14 & 82482.99 & 84608.84 & 86734.69 & + \\
\hline Holding & 6220.65 & 6220.65 & 6220.65 & 6220.65 & 6220.65 & 6220.65 & 6220.65 & 6220.65 & 6220.65 & 0.00 \\
\hline Waiting & 26.14 & 26.14 & 26.14 & 26.14 & 26.14 & 26.14 & 26.14 & 26.14 & 26.14 & 0.00 \\
\hline$E[T P U(y)]$ & 1247880.57 & 1245754.72 & 1243628.87 & 1241503.02 & 1239377.17 & 1237251.32 & 1235125.47 & 1232999.62 & 1230873.77 & - \\
\hline$\%$ & 0.69 & 0.51 & 0.34 & 0.17 & 0.00 & -0.17 & -0.34 & -0.51 & -0.69 & - \\
\hline
\end{tabular}

and leading the variation of the probability of the typeI inspection error is prioritized.

Table 6 shows the changes of total profit per unit time according to the variations in parameter $c_{r}$ (cost of rejecting a non-defective item). This parameter varies between $\$ 15$ and $\$ 45$. As can be expected, the optimal order size remains constant with an increase in $c_{r}$. Table 6 confirms that $c_{r}$ does not affect any of the revenue components and, therefore, has no effect on the total revenue per unit time. In contrast, the total cost per unit time has increased as $\$ 61224.49$, and the only reason is the increase of inspection error cost to this value. Moreover, the remaining costs remain unchanged. As a result, the total profit per unit time will decrease as the total cost per unit time increases.
The last row of the table shows that the change in profit per unit time, according to the $c_{r}$, is linear and has a significant impact on profit.

Table 7 shows the changes of total profit per unit time according to variations in the parameter $c_{a}$ (cost of accepting a defective item). We will change this parameter in the range of $\$ 100$ to $\$ 300$. As it is obvious, $c_{a}$ does not play a role in optimal lot size formula and, therefore, the optimal order size does not change with its variations. As we expected, an increase in the $c_{a}$ only increases the inspection error cost, which leads to an increase in the total cost per unit time and a decrease in total profit per unit time as the same amount.

Figure 5 shows the graph of changes for total profit per unit time for two parameters $c_{a}$ and $c_{r}$ in 


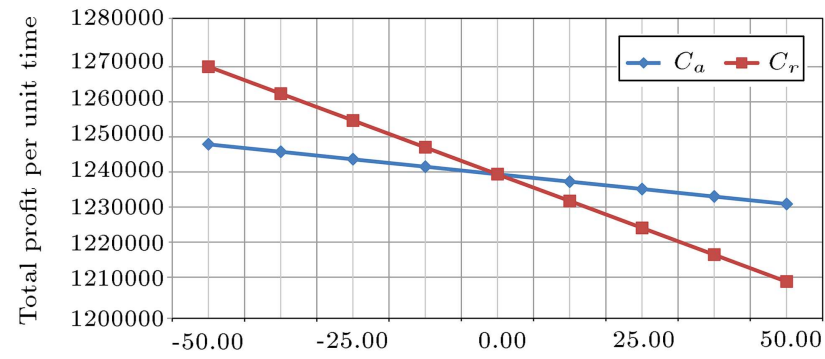

Figure 5. The effect of changes in the cost of rejecting a non-defective item $c_{r}$ and the cost of accepting a defective item $c_{a}$ on total profit per unit time.

the range of $-50 \%$ and $50 \%$. As shown in this figure, increasing both parameters will reduce total profit per unit. Moreover, this figure shows that the growth of the parameter affects $c_{a}$ the profit value with a slower gradient than the parameter $c_{r}$. The point that can cause ambiguity in analyzing the sensitivity of these two parameters is their range of variations. The parameter $c_{a}$ has changed between $\$ 100$ and $\$ 300$ and has more severe variations than $c_{r}$ that fluctuates between $\$ 15$ and $\$ 45$. The nature of the two parameters is the same, but unexpectedly the total profit per unit time of the model is more sensitive to $c_{r}$. The cause is the coefficient that is multiplied by two parameters in each cycle. The $c_{a}$, although bigger, is multiplied by the coefficient $y p \beta$, but the $c_{r}$ parameter takes coefficient $y(1-p) \alpha$. In the numerical example, $y \alpha$ is equal to $y \beta$, but $p=0.04$ and $1-p=0.96$, which proves the logic of the above contradiction. Therefore, although $c_{r}$ has a smaller value, its decrease makes it more profitable than $c_{a}$.

Table 8 shows the changes in total profit per unit time according to the changes in the parameter $\pi$ (the waiting cost per unit time). This table changes the value of the parameter $\pi$ from $-50 \%$ to $50 \%$ while leaving the remaining parameters unchanged. By increasing the value of the parameter $\pi$, the order size must be reduced, which is supported by the results presented in this table. Despite a decrease in the optimal batch size, separated revenues per unit time and, consequently, total revenues per unit time remain constant because they are independent of the order size and the waiting cost per unit time. Moreover, following the mentioned change, procurement costs, inspection error costs, and waiting costs are rising and holding costs are reduced. According to the results presented in the table, the sensitivity of total profit per unit time, with respect to the parameter $\pi$, is insignificant.

Figure 6 shows variations of total profit per unit time through variations in the parameter $\pi$ in the range of $-50 \%$ to $50 \%$. As it is clear in this figure, the parameter $\pi$ has an inverse relationship with total profit per unit time. Furthermore, total profit variations are quite low due to the low sensitivity of optimal order size to this parameter, which causes little variations in procurement cost, inspection error costs, and holding cost.

Table 9 shows the variations of total profit per unit time according to the changes in parameter $w$ (the number of discounted sales of returned items per cycle). We change the parameter $w$ from 4 to 12 times bigger to examine the fluctuations of all components of total profit and order size. Obviously, optimal order size increases upon increasing the parameter $w$. Changing this parameter does not make any difference in the components of total revenues per unit time. As it is shown in Table 9, regular inspection cost, special inspection

Table 8. Sensitivity analysis of the waiting cost per unit time $\pi$.

\begin{tabular}{|c|c|c|c|c|c|c|c|c|c|c|}
\hline$\pi$ & 6.00 & 7.50 & 9.00 & 10.50 & 12.00 & 13.50 & 15.00 & 16.50 & 18.00 & $a n$ \\
\hline$\%$ & -50.00 & -37.50 & -25.00 & -12.50 & 0.00 & 12.50 & 25.00 & 37.50 & 50.00 & \\
\hline$y_{2}^{*}$ & 2725.34 & 2724.63 & 2723.91 & 2723.20 & 2722.49 & 2721.78 & 2721.06 & 2720.35 & 2719.64 & - \\
\hline$E[T R U(y)]$ & 4625850.34 & 4625850.34 & 4625850.34 & 4625850.34 & 4625850.34 & 4625850.34 & 4625850.34 & 4625850.34 & 4625850.34 & 0.00 \\
\hline $\begin{array}{l}\text { Sales (non- } \\
\text { defective items) }\end{array}$ & 4500000.00 & 4500000.00 & 4500000.00 & 4500000.00 & 4500000.00 & 4500000.00 & 4500000.00 & 4500000.00 & 4500000.00 & 0.00 \\
\hline $\begin{array}{l}\text { Sales (defective } \\
\text { recognized items) }\end{array}$ & 124149.66 & 124149.66 & 124149.66 & 124149.66 & 124149.66 & 124149.66 & 124149.66 & 124149.66 & 124149.66 & 0.00 \\
\hline $\begin{array}{l}\text { Sales (items } \\
\text { returned from market) }\end{array}$ & 1700.68 & 1700.68 & 1700.68 & 1700.68 & 1700.68 & 1700.68 & 1700.68 & 1700.68 & 1700.68 & 0.00 \\
\hline$E[T C U(y)]$ & 3386460.10 & 3386463.37 & 3386466.63 & 3386469.90 & 3386473.17 & 3386476.44 & 3386479.70 & 3386482.97 & 3386486.23 & + \\
\hline Procurement & 3195015.76 & 3195017.40 & 3195019.03 & 3195020.67 & 3195022.30 & 3195023.93 & 3195025.57 & 3195027.20 & 3195028.83 & + \\
\hline Regular inspection & 106292.52 & 106292.52 & 106292.52 & 106292.52 & 106292.52 & 106292.52 & 106292.52 & 106292.52 & 106292.52 & 0.00 \\
\hline Special inspection & 680.27 & 680.27 & 680.27 & 680.27 & 680.27 & 680.27 & 680.27 & 680.27 & 680.27 & 0.00 \\
\hline Inspection errors & 78231.29 & 78231.29 & 78231.29 & 78231.29 & 78231.29 & 78231.29 & 78231.29 & 78231.29 & 78231.29 & + \\
\hline Holding & 6227.17 & 6225.54 & 6223.91 & 6222.28 & 6220.65 & 6219.03 & 6217.40 & 6215.78 & 6214.16 & - \\
\hline Waiting & 13.08 & 16.35 & 19.61 & 22.87 & 26.14 & 29.40 & 32.65 & 35.91 & 39.16 & + \\
\hline$E[T P U(y)]$ & 1239390.24 & 1239386.97 & 1239383.71 & 1239380.44 & 1239377.17 & 1239373.90 & 1239370.64 & 1239367.37 & 1239364.11 & - \\
\hline$\%$ & 0.0011 & 0.0008 & 0.0005 & 0.0003 & 0.0000 & -0.0003 & -0.0005 & -0.0008 & -0.0011 & - \\
\hline
\end{tabular}


Table 9. sensitivity analysis of the number of discounted sales of returned items per cycle $w$ results.

\begin{tabular}{|c|c|c|c|c|c|c|c|c|c|c|}
\hline$w$ & 4.00 & 5.00 & 6.00 & 7.00 & 8.00 & 9.00 & 10.00 & 11.00 & 12.00 & Change \\
\hline$\%$ & -50.00 & -37.50 & -25.00 & -12.50 & 0.00 & 12.50 & 25.00 & 37.50 & 50.00 & \\
\hline$y_{2}^{*}$ & 2722.37 & 2722.42 & 2722.45 & 2722.47 & 2722.49 & 2722.50 & 2722.51 & 2722.52 & 2722.53 & + \\
\hline$E[T R U(y)]$ & 4625850.34 & 4625850.34 & 4625850.34 & 4625850.34 & 4625850.34 & 4625850.34 & 4625850.34 & 4625850.34 & 4625850.34 & 0.00 \\
\hline $\begin{array}{l}\text { Sales (non- } \\
\text { defective items) }\end{array}$ & 4500000.00 & 4500000.00 & 4500000.00 & 4500000.00 & 4500000.00 & 4500000.00 & 4500000.00 & 4500000.00 & 4500000.00 & 0.00 \\
\hline $\begin{array}{l}\text { Sales (defective } \\
\text { recognized items) }\end{array}$ & 124149.66 & 124149.66 & 124149.66 & 124149.66 & 124149.66 & 124149.66 & 124149.66 & 124149.66 & 124149.66 & 0.00 \\
\hline $\begin{array}{l}\text { Sales (items } \\
\text { returned from market) }\end{array}$ & 1700.68 & 1700.68 & 1700.68 & 1700.68 & 1700.68 & 1700.68 & 1700.68 & 1700.68 & 1700.68 & 0.00 \\
\hline $\mathrm{E}[\mathrm{TCU}(\mathrm{y})]$ & 3386473.72 & 3386473.50 & 3386473.35 & 3386473.25 & 3386473.17 & 3386473.11 & 3386473.06 & 3386473.02 & 3386472.99 & - \\
\hline Procurement & 3195022.57 & 3195022.46 & 3195022.39 & 3195022.34 & 3195022.30 & 3195022.27 & 3195022.25 & 3195022.23 & 3195022.21 & - \\
\hline Regular inspection & 106292.52 & 106292.52 & 106292.52 & 106292.52 & 106292.52 & 106292.52 & 106292.52 & 106292.52 & 106292.52 & 0.00 \\
\hline Special inspection & 680.27 & 680.27 & 680.27 & 680.27 & 680.27 & 680.27 & 680.27 & 680.27 & 680.27 & 0.00 \\
\hline Inspection errors & 78231.29 & 78231.29 & 78231.29 & 78231.29 & 78231.29 & 78231.29 & 78231.29 & 78231.29 & 78231.29 & 0.00 \\
\hline Holding & 6220.93 & 6220.82 & 6220.74 & 6220.69 & 6220.65 & 6220.62 & 6220.60 & 6220.58 & 6220.56 & - \\
\hline Waiting & 26.13 & 26.14 & 26.14 & 26.14 & 26.14 & 26.14 & 26.14 & 26.14 & 26.14 & 0.00 \\
\hline$E[T P U(y)]$ & 1239376.63 & 1239376.84 & 1239376.99 & 1239377.09 & 1239377.17 & 1239377.23 & 1239377.28 & 1239377.32 & 1239377.35 & + \\
\hline$\%$ & -0.000044 & -0.000026 & -0.000015 & -0.000006 & 0.000000 & 0.000005 & 0.000009 & 0.000012 & 0.000015 & + \\
\hline
\end{tabular}

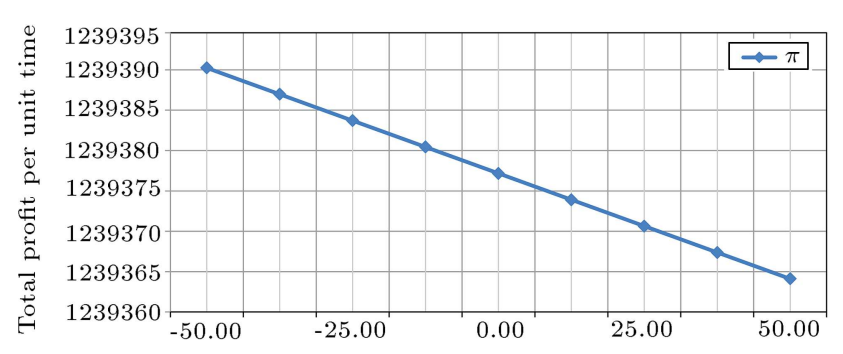

Figure 6. The effect of changes in the waiting cost per unit time $\pi$ on total profit per unit time.

cost, inspection errors cost, and waiting cost are fixed, but procurement and holding costs are decreasing by increasing $w$, which result in an increase in total profit per unit time. Of course, the important point is that the total profit per unit time is less than $\$ 1$ in the range of changes. The last row of the table clearly shows that this parameter has special properties over the six previous parameters. First, in contrast to the remaining parameters, there is a direct relationship with total profit per unit time. Second, its sensitivity analysis is nonlinear and third, for the total profit per unit time, it is the most non-sensitive parameter until now.

Figure 7 shows variations of total profit per unit time through variations in the parameter $w$ in the range of $-50 \%$ to $50 \%$ of its original amounts. As it is expected from the results in Table 9 , the variations are nonlinear and exponential; however, the intensity of total profit variations per unit time is so low. The reason for this is that the parameter $w$ is a part of the holding cost, and the total holding cost is only $0.2 \%$ of the total cost. In fact, its fluctuation, although is high on the holding cost scale, does not have much effect on total profit per unit time.

Table 10 shows the variations of total profit

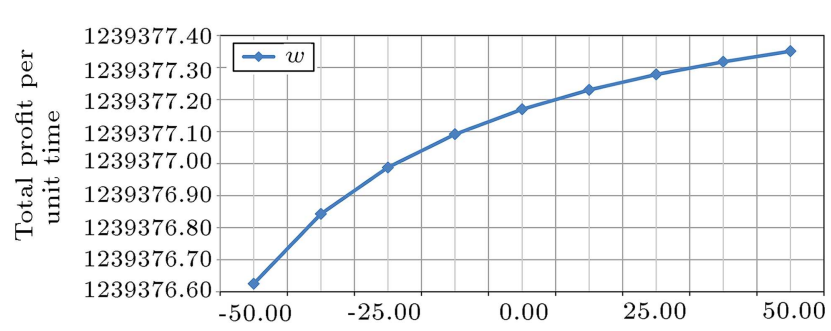

Figure 7. The effect of changes in the number of discounted sales of return items per cycle $w$ on total profit per unit time.

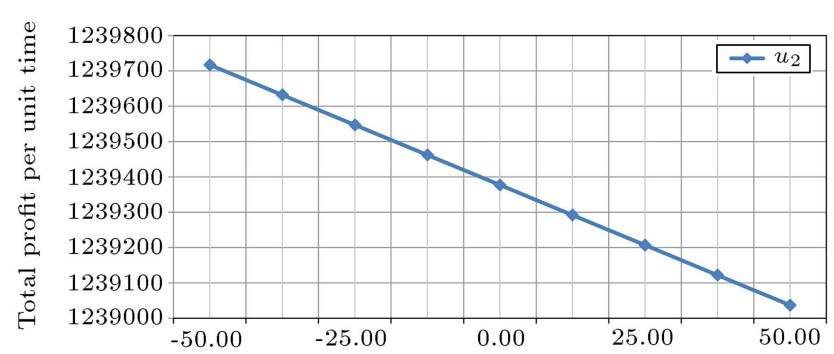

Figure 8. The effect of changes in special inspection cost per unit for Case $2 u_{2}$ on total profit per unit time.

per unit time according to the parameter $u_{2}$ (special inspection cost per unit for Case 2). We will change $u_{2}$ between $\$ 4$ and $\$ 12$ to see how it affects total profit per unit time. Changing this parameter has no effect on the optimal order size. The last column of the table also indicates that the remaining components of total profit per unit time do not change and the profit will decrease exactly to the same amount.

Figure 8 shows variations of total profit per unit time for the parameter $u_{2}$ in the range of $-50 \%$ to $50 \%$. It is clear that parameter $u_{2}$ has an inverse relationship with the total profit per unit time. Of course, by 
Table 10. Sensitivity analysis of special inspection cost per unit for Case $2 u_{2}$ results.

\begin{tabular}{|c|c|c|c|c|c|c|c|c|c|c|}
\hline$u_{2}$ & 4.00 & 5.00 & 6.00 & 7.00 & 8.00 & 9.00 & 10.00 & 11.00 & 12.00 & Change \\
\hline$\%$ & -50.00 & -37.50 & -25.00 & -12.50 & 0.00 & 12.50 & 25.00 & 37.50 & 50.00 & \\
\hline$y_{2}^{*}$ & 2722.49 & 2722.49 & 2722.49 & 2722.49 & 2722.49 & 2722.49 & 2722.49 & 2722.49 & 2722.49 & 0.00 \\
\hline$E[T R U(y)]$ & 4625850.34 & 4625850.34 & 4625850.34 & 4625850.34 & 4625850.34 & 4625850.34 & 4625850.34 & 4625850.34 & 4625850.34 & 0.00 \\
\hline $\begin{array}{l}\text { Sales (non- } \\
\text { defective items) }\end{array}$ & 4500000.00 & 4500000.00 & 4500000.00 & 4500000.00 & 4500000.00 & 4500000.00 & 4500000.00 & 4500000.00 & 4500000.00 & 0.00 \\
\hline $\begin{array}{l}\text { Sales (defective } \\
\text { recognized items) }\end{array}$ & 124149.66 & 124149.66 & 124149.66 & 124149.66 & 124149.66 & 124149.66 & 124149.66 & 124149.66 & 124149.66 & 0.00 \\
\hline $\begin{array}{l}\text { Sales (items } \\
\text { returned from market) }\end{array}$ & 1700.68 & 1700.68 & 1700.68 & 1700.68 & 1700.68 & 1700.68 & 1700.68 & 1700.68 & 1700.68 & 0.00 \\
\hline$E[T C U(y)]$ & 3386133.03 & 3386218.07 & 3386303.10 & 3386388.14 & 3386473.17 & 3386558.20 & 3386643.24 & 3386728.27 & 3386813.31 & + \\
\hline Procurement & 3195022.30 & 3195022.30 & 3195022.30 & 3195022.30 & 3195022.30 & 3195022.30 & 3195022.30 & 3195022.30 & 3195022.30 & 0.00 \\
\hline Regular inspection & 106292.52 & 106292.52 & 106292.52 & 106292.52 & 106292.52 & 106292.52 & 106292.52 & 106292.52 & 106292.52 & 0.00 \\
\hline Special inspection & 340.14 & 425.17 & 510.20 & 595.24 & 680.27 & 765.31 & 850.34 & 935.37 & 1020.41 & + \\
\hline Inspection errors & 78231.29 & 78231.29 & 78231.29 & 78231.29 & 78231.29 & 78231.29 & 78231.29 & 78231.29 & 78231.29 & 0.00 \\
\hline Holding & 6220.65 & 6220.65 & 6220.65 & 6220.65 & 6220.65 & 6220.65 & 6220.65 & 6220.65 & 6220.65 & 0.00 \\
\hline Waiting & 26.14 & 26.14 & 26.14 & 26.14 & 26.14 & 26.14 & 26.14 & 26.14 & 26.14 & 0.00 \\
\hline$E[T P U(y)]$ & 1239717.31 & 1239632.27 & 1239547.24 & 1239462.20 & 1239377.17 & 1239292.14 & 1239207.10 & 1239122.07 & 1239037.03 & - \\
\hline$\%$ & 0.027 & 0.021 & 0.014 & 0.007 & 0.000 & -0.007 & -0.014 & -0.021 & -0.027 & - \\
\hline
\end{tabular}

increasing the special inspection cost per unit from $\$ 4$ to $\$ 12$, the total profit increased only by $0.0005 \%$; therefore, controlling this parameter or attempting to decrease it would have little effect on total profit rise.

\section{Conclusions}

In this paper, the classical Economic Order Quantity (EOQ) model was developed for a case in which the order batch contains some defective items and there are possible inspection errors (types I and II) that may occur in recognizing the defective items. Nowadays, most customers prefer to receive non-defective items; however, it is possible due to type-II error. This unpleasant experience could reduce the credibility of the vendor or even make lost sales. Hence, we added a special inspection process, which was performed immediately after the regular inspection process, to prevent delivering more than one defective item to customers. For this purpose, at the end of the special inspection process, batch replacement was carried out for satisfying demand for the returned sales items. In addition, we provided multiple sales opportunities for returning items from the market, which gives more flexibility to the model. Then, we presented two cases based on the length of the special inspection process. The first case considers the insignificant length of the special inspection, while the second case assumed the length of the inspection process to be maximum possible time. The concavity was proved for the total profit per unit time of both cases, and then the optimal order size was derived for both cases analytically. A numerical example was presented to compare the two cases and analyze the results. The numerical example showed the superiority of Case 2 against Case 1 in terms of total profit per unit time. The greater profitability of Case 2 resulted from greater savings in the special inspection cost than Case 1. Finally, we performed a comprehensive analysis of sensitivity for the main parameters of the problem. The results indicated that by increasing the probability that an item is defective $p$, the type-I error probability $\alpha$, the type-II error probability $\beta$, the cost of rejecting a nondefective item $c_{r}$, the cost of accepting a defective item $c_{a}$, the waiting cost per unit time $\pi$ and the special inspection cost per unit $u_{2}$, and the total profit per unit time will decrease; in contrast, increase in the number of discounted sales of returned items per cycle $w$ increases profit per unit time. The total profit per unit time had high sensitivity to the parameters such as type-I error probability $\alpha$, the probability that an item is defective $p$ and the cost of rejecting a nondefective item $c_{r}$, and slight sensitivity to the number of discounted sales of returned items per cycle $w$ and the waiting cost per unit time $\pi$.

As an interesting area for future research, this study can be extended to a case which assumes that the special inspection time is a function with respect to 
special inspection cost per unit. Moreover, the holding cost for perfect quality items can be different from that of imperfect quality items. Another interesting area for future study is the extension of this model for cases with scrap, reject or repairable items. Further, the proposed inventory problem can be incorporated into the concepts of pricing, quantitative discounts for purchasing, and delay in payment.

\section{References}

1. Sadigh, A.N., Chaharsooghi, S.K., and Sheikhmohammady, M. "Game-theoretic analysis of coordinating pricing and marketing decisions in a multi-product multi-echelon supply chain", Scientia Iranica. Transactions E, Industrial Engineering, 23(3), p. 1459 (2016).

2. Parsaeifar, S., Bozorgi-Amiri, A., Naimi-Sadigh, A., and Sangari, M.S. "A game theoretical for coordination of pricing, recycling, and green product decisions in the supply chain", Journal of Cleaner Production, 226, pp. 37-49 (2019).

3. Salameh, M.K. and Jaber, M.Y. "Economic production quantity model for items with imperfect quality", International Journal of Production Economics, 64(13), pp. 59-64 (2000).

4. Hayek, P.A. and Salameh, M.K. "Production lot sizing with the reworking of imperfect quality items produced", Production Planning \& Control, 12(6), pp. 584-590 (2001).

5. Chiu, S.W., Gong, D.C., and Wee, H.M. "Effects of random defective rate and imperfect rework process on economic production quantity model", Japan Journal of Industrial and Applied Mathematics, 21(3), p. 375 (2004).

6. Rezaei, J. "Economic order quantity model with backorder for imperfect quality items", Int. Engineering Management Conf., St. John's, Newfoundland \& Labrador, Canada, pp. 466-470 (2005).

7. Wee, H.M., Yu, J., and Chen, M.C. "Optimal inventory model for items with imperfect quality and shortage backordering", Omega, 35(1), pp. 7-11 (2007).

8. Jaber, M.Y., Goyal, S.K., and Imran, M. "Economic production quantity model for items with imperfect quality subject to learning effects", International Journal of Production Economics, 115(1), pp. 143-150 (2008).

9. Rezaei, J. and Davoodi, M. "A deterministic, multiitem inventory model with supplier selection and imperfect quality", Applied Mathematical Modelling, 32(10), pp. 2106-2116 (2008).

10. Chung, K.J., Her, C.C., and Lin, S.D. "A twowarehouse inventory model with imperfect quality production processes", Computers \& Industrial Engineering, 56(1), pp. 193-197 (2009).

11. Chang, H.C. and Ho, C.H. "Exact closed-form solutions for "optimal inventory model for items with imperfect quality and shortage backordering", Omega, 38(3-4), pp. 233-237 (2010).

12. Khan, M., Jaber, M.Y., Guiffrida, A.L., and Zolfaghari, S. "A review of the extensions of a modified EOQ model for imperfect quality items", International Journal of Production Economics, 132(1), pp. 1-12 (2011).

13. Al-Salamah, M. "Economic order quantity with imperfect quality, destructive testing acceptance sampling, and inspection errors", Advances in Management and Applied Economics, 1(2), p. 59 (2011).

14. Tsou, J.C., Hejazi, S.R., and Barzoki, M.R. "Economic production quantity model for items with continuous quality characteristic, rework and reject", International Journal of Systems Science, 43(12), pp. 22612267 (2012).

15. Jaber, M.Y., Zanoni, S., and Zavanella, L.E. "Economic order quantity models for imperfect items with buy and repair options", International Journal of Production Economics, 155, pp. 126-131 (2014).

16. Vishkaei, B.M., Niaki, S.T.A., Farhangi, M., and Rashti, M.E.M. "Optimal lot sizing in screening processes with returnable defective items", Journal of Industrial Engineering International, 10(3), p. 70 (2014).

17. Mezei, J. and Björk, K.M. "An economic production quantity problem with backorders and fuzzy cycle times", Journal of Intelligent \& Fuzzy Systems, 28(4), pp. 1861-1868 (2015).

18. Farhangi, M., Niaki, S.T.A., and Vishkaei, B.M. "Closed-form equations for optimal lot sizing in deterministic EOQ models with exchangeable imperfect quality items", Scientia Iranica, Transaction E, Industrial Engineering, 22(6), p. 2621 (2015).

19. Zhou, Y.W., Chen, J., Wu, Y., and Zhou, W. "EPQ models for items with imperfect quality and onetime-only discount", Applied Mathematical Modelling, 39(3-4), pp. 1000-1018 (2015).

20. Hsu, L.F. and Hsu, J.T. "Economic production quantity (EPQ) models under an imperfect production process with shortages backordered", International Journal of Systems Science, 47(4), pp. 852-867 (2016).

21. Datta, T.K. "Inventory system with defective products and investment opportunity for reducing defective proportion", Operational Research, 17(1), pp. 297-312 (2017).

22. Abdel-Aleem, A., El-Sharief, M.A., Hassan, M.A., and El-Sebaie, M.G. "A surface response optimization model for EPQ system with imperfect production process under rework and shortage", Opsearch, 54(4), pp. $735-751$ (2017).

23. Jaggi, C.K., Cárdenas-Barrón, L.E., Tiwari, S., and Shafi, A.A. "Two-warehouse inventory model for deteriorating items with imperfect quality under the conditions of permissible delay in payments", Scientia Iranica, Transaction E, Industrial Engineering, 24(1), p. 390 (2017). 
24. Taleizadeh, A.A., Sari-Khanbaglo, M.P., and Cárdenas -Barrón, L.E. "Outsourcing rework of imperfect items in the economic production quantity (EPQ) inventory model with backordered demand", IEEE Transactions on Systems, Man, and Cybernetics: Systems, pp. 1-12 (2017).

DOI: 10.1109/TSMC.2017.2778943

25. Mokhtari, H. "A joint internal production and external supplier order lot size optimization under defective manufacturing and rework", The International Journal of Advanced Manufacturing Technology, 95(1-4), pp. 1039-1058 (2018).

26. Liao, J.J., Huang, K.N., Chung, K.J., Lin, S.D., Ting, P.S., and Srivastava, H.M. "Retailer's optimal ordering policy in the EOQ model with imperfect-quality items under limited storage capacity and permissible delay", Mathematical Methods in the Applied Sciences, 41(17), pp. 7624-7640 (2018).

27. Cheng, Y.L., Wang, W.T., Wei, C.C., and Lee, K.L. "An integrated lot-sizing model for imperfect production with multiple disposals of defective items", Scientia Iranica, 25(2), pp. 852-867 (2018).

28. Mokhtari, H. "Optimal lot size in a manufacturing system with imperfect raw materials and defective finished products", Scientia Iranica, Transaction E, Industrial Engineering, 26(4), pp. 2561-2578 (2019).

29. Mokhtari, H. and Asadkhani, J. "Extended economic production quantity models with preventive maintenance", Scientia Iranica, Transaction E, Industrial Engineering, 27(6), pp. 3253-3264 (2020).

30. Nobil, A.H., Afshar Sedigh, A.H., Tiwari, S., and Wee, H.M. "An imperfect multi-item single machine production system with shortage, rework, and scrapped considering inspection, dissimilar deficiency levels, and non-zero setup times", Scientia Iranica, 26(1), pp. 557-570 (2019).

31. Yoo, S.H., Kim, D., and Park, M.S. "Economic production quantity model with imperfect-quality items, two-way imperfect inspection and sales return", International Journal of Production Economics, 121(1), pp. 255-265 (2009).

32. Khan, M., Jaber, M.Y., and Bonney, M. "An economic order quantity (EOQ) for items with imperfect quality and inspection errors", International Journal of Production Economics, 133(1), pp. 113-118 (2011).

33. Lin, T.Y. and Chen, M.T. "An economic order quantity model with screening errors, returned cost, and shortages under quantity discounts", African Journal of Business Management, 5(4), pp. 1129-1135 (2011).

34. Hsu, L.F. "A note on an economic order quantity (EOQ) for items with imperfect quality and inspection errors", International Journal of Industrial Engineering Computations, 3(4), pp. 695-702 (2012).

35. Hsu, J.T. and Hsu, L.F. "Two EPQ models with imperfect production processes, inspection errors, planned backorders, and sales returns", Computers \& Industrial Engineering, 64(1), pp. 389-402 (2013).
36. Sharifi, E., Sobhanallahi, M.A., Mirzazadeh, A., and Shabani, S. "An EOQ model for imperfect quality items with partial backordering under screening errors", Cogent Engineering, 2(1), p. 994258 (2015).

37. Chang, C.T., Cheng, M.C., and Soong, P.Y. "Impacts of inspection errors and trade credits on the economic order quantity model for items with imperfect quality", International Journal of Systems Science: Operations \& Logistics, 3(1), pp. 34-48 (2016).

38. Aggarwal, K.K. and Aneja, S. "An EOQ model with inspection error, rework and sales return", International Journal of Advanced Operations Management, 8(3), pp. 185-199 (2016).

39. Jauhari, W.A., Sofiana, A., Kurdhi, N.A., and Laksono, P.W. "An integrated inventory model for supplier-manufacturer-retailer system with imperfect quality and inspection errors", International Journal of Logistics Systems and Management, 24(3), pp. 383407 (2016).

40. Zhou, Y., Chen, C., Li, C., and Zhong, Y. "A synergic economic order quantity model with trade credit, shortages, imperfect quality and inspection errors", Applied Mathematical Modelling, 40(2), pp. 1012-1028 (2016).

41. Khanna, A., Kishore, A., and Jaggi, C.K. "Inventory modeling for imperfect production process with inspection errors, sales return, and imperfect rework process", International Journal of Mathematical, Engineering and Management. Sciences, 2(42), pp. 242258 (2017).

42. Sofiana, A. and Rosyidi, C.N. "Integrated vendorbuyer inventory model considering imperfect quality and inspection errors with controllable lead time", Int. Conf. on Industrial Engineering and Engineering Management (IEEM), Singapore, pp. 1321-1325 (2017).

43. Khan, M., Hussain, M., and Cárdenas-Barrón, L.E. "Learning and screening errors in an EPQ inventory model for supply chains with stochastic lead time demands", International Journal of Production Research, 55(16), pp. 4816-4832 (2017).

44. Pal, S. and Mahapatra, G.S. "A manufacturingoriented supply chain model for imperfect quality with inspection errors, stochastic demand under rework and shortages", Computers \& Industrial Engineering, 106, pp. 299-314 (2017).

45. Wangsa, I.D. and Wee, H.M. "A vendor-buyer inventory model for defective items with errors in inspection, stochastic lead time and freight cost", INFOR: Information Systems and Operational Research, pp. 1-26 (2019). DOI: 10.1080/03155986.2019.1607807

\section{Biographies}

Hadi Mokhtari is currently an Associate Professor of Industrial Engineering in University of Kashan, Iran. His current research interests include the applications of operations research and artificial intelligence techniques to the areas of project scheduling, production 
scheduling, manufacturing supply chains, and engineering economic problems. He also published several papers in international journals such as Computers and Operations Research, International Journal of Production Research, Applied Soft Computing, Neurocomputing, International Journal of Advanced Manufacturing Technology, IEEE Transactions on Engineering Man- agement, and Expert Systems with Applications.

Javad Asadkhani is currently an MSc student of Executive MBA in University of Kashan, Iran. His current research interests include the applications of operations research and inventory problems to the area of supply chain management. 